\title{
Dynamic Monitoring of Plant Cover and Soil Erosion Using Remote Sensing, Mathematical Modeling, Computer Simulation and GIS Techniques
}

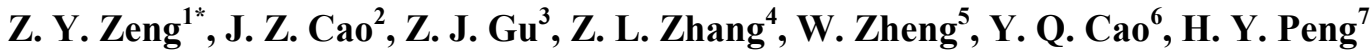 \\ ${ }^{1}$ College of Geographical Science, Nanjing Normal University, Nanjing, China; ${ }^{2}$ Dandong Center for Oases Research, Dandong, \\ China; ${ }^{3}$ School of Bio-Chemical and Environmental Engineering, Nanjing Xiaozhuang University, Nanjing, China; ${ }^{4}$ School of Ar- \\ chitecture and Urban Planning, Suzhou University of Science and Technology, Suzhou, China; ${ }^{5}$ National Satellite Meteorological \\ Center, Meteorological Administration, Beijing, China; ${ }^{6}$ Dandong Bureau of Environment Protection, Dandong, China; ${ }^{7}$ Nanjing \\ Institute of Soil Science, Chinese Academy of Sciences, Nanjing, China.
}

Email: * zengzhiyuangm@gmail.com

Received April 24 $4^{\text {th }}, 2013$; revised May $6^{\text {th }}, 2013$; accepted June $17^{\text {th }}, 2013$

Copyright (C) 2013 Z. Y. Zeng et al. This is an open access article distributed under the Creative Commons Attribution License, which permits unrestricted use, distribution, and reproduction in any medium, provided the original work is properly cited.

\begin{abstract}
Dynamic monitoring of plant cover and soil erosion often uses remote sensing data, especially for estimating the plant cover rate (vegetation coverage) by vegetation index. However, the latter is influenced by atmospheric effects and methods for correcting them are still imperfect and disputed. This research supposed and practiced an indirect, fast, and operational method to conduct atmospheric correction of images for getting comparable vegetation index values in different times. It tries to find a variable free from atmospheric effects, e.g., the mean vegetation coverage value of the whole study area, as a basis to reduce atmospheric correction parameters by establishing mathematical models and conducting simulation calculations. Using these parameters, the images can be atmospherically corrected. And then, the vegetation index and corresponding vegetation coverage values for all pixels, the vegetation coverage maps and coverage grade maps for different years were calculated, i.e., the plant cover monitoring was realized. Using the vegetation coverage grade maps and the ground slope grade map from a DEM to generate soil erosion grade maps for different years, the soil erosion monitoring was also realized. The results show that in the study area the vegetation coverage was the lowest in 1976, much better in 1989, but a bit worse again in 2001. Towards the soil erosion, it had been mitigated continuously from 1976 to 1989 and then to 2001. It is interesting that a little decrease of vegetation coverage from 1989 to 2001 did not lead to increase of soil erosion. The reason is that the decrease of vegetation coverage was chiefly caused by urbanization and thus mainly occurred in very gentle terrains, where soil erosion was naturally slight. The results clearly indicate the details of plant cover and soil erosion change in 25 years and also offer a scientific foundation for plant and soil conservation.
\end{abstract}

Keywords: Atmospheric Correction; Field Measurement; Modeling; Regression; Simulation; Soil Erosion; Vegetation Coverage; Vegetation Index

\section{Introduction}

Dynamic monitoring of plant cover and soil erosion is very important for land use research and environment management. Plant cover monitoring has been conducted by using field observation, remote sensing, mathematic modeling, simulation, GIS, and GPS techniques [1-7]. Remote sensing techniques usually comprise visual airphoto or satellite image interpretation and digital image classification [8,9]. Besides, various vegetation indices,

\footnotetext{
${ }^{*}$ Corresponding author.
}

especially the Normalized Difference Vegetation Index (NDVI) are also adopted and extensively used [10-15]. And for soil erosion monitoring as an application of vegetation monitoring, GIS techniques and Universal Soil Loss Equation (USLE) with its various versions are often used too [16,17]. Gaffer et al. [17] indicated that a geographical information system software package and a modified Universal Soil Loss Equation were used to estimate erosion potential. Winchell et al. [18] also stated that the GIS-based approach was shown to produce statistical distributions of the revised USLE length-slope 
factor values very similar to those described by the National Resources Inventory database of field measurements $[16,19]$. Some researchers also pointed out the problems with the vegetation indices, e.g. their sensitivity to atmospheric conditions [13]; their variation due to the sun angle [20]; their variability induced by the topography [21]; etc. As Rundquist [13] indicated, "the Normalized Difference Vegetation Index (NDVI) has been criticized because of its sensitivity to atmospheric conditions". Some insufficiencies also exist with other methods. For example, for the method of visual interpretation and digital classification, the quantization level and accuracy are still lower [22,23]. Some researchers also pointed out the problems with the USLE method. As Saha [19] pointed out, "the greatest criticism has been its ineffectiveness in applications outside the range of conditions for which it was developed". And as Wang et al. [16] stated clearly, "because of the multiple factors, their interactions, and their spatial and temporal variability, accurately mapping the factors and further soil loss is very difficult".

Let us return to the method of vegetation index. We think that its main problem is the atmospheric effect. The index values computed from original satellite images in different times are incomparable because of the atmospheric effects, so the monitoring results by using the original vegetation index are generally far from the objective reality and unacceptable [23]. Consequently, the atmospheric correction is needed $[13,20]$. Up to now numerous methods of atmospheric correction have been offered and applied and many useful results have been obtained $[24,25]$. Generally speaking, these methods can roughly be divided into two categories: 1) more accurate methods such as the $6 \mathrm{~S}$ model [26];2) simpler methods such as the minimum value subtraction method [27]. However, more accurate methods generally demand so-called synchronous meteorological parameters, even through ground-measured reference data. But these data are difficult to acquire, very costly or provided only based on limited ground points. And especially for most historical satellite scenes, such data are not available and even for planned acquisitions, they may also be hard to acquire $[25,28]$. Moreover, Mather [29] even indicated: "Several methods for the atmospheric correction of remotely-sensed images have been reported in the literature; none is universally applicable". Singh et al. [14] also mentioned: "Numerous algorithms have been developed for correction of noise due to different sources, ... however, complete physical ground corrections for all the effects and for various land surfaces are not yet available." As to the less accurate methods, their corrected results do not have enough accuracy for our monitoring task (Zeng, 2004) [23].
Since the late 1990s, along another train of thought, we have been developing and testing a new practical and fast method. It is another choice. In this method, the atmospheric correction of the vegetation index values is conducted by an indirect way with the help of seeking for one or more correct reference variables uninfluenced by atmosphere, e.g. the mean vegetation coverage value of whole study area. Based on the reference variable, the atmospheric correction parameters can be deduced and the images can be corrected. Then, using the corrected vegetation indices and corresponding vegetation coverage values, the vegetation monitoring can be realized. Vegetation coverage grade maps and ground slope grade map (from DEM) can generate soil erosion grade maps and so the soil erosion change in different years can be judged. In fact, the method of using vegetation coverage map and ground slope map to generate soil erosion map has been adopted by some other researchers. For example, Hazarika et al. [20] used to write: "A soil erosion model was developed to integrate NDVI and land slope to estimate the soil erosion rate and the vegetation cover is a major factor of soil erosion. Therefore, a Normalized Difference Vegetation Index derived from remote sensing (Landsat ${ }^{\mathrm{TM}}$ ) was used to assess the vegetation cover." Wang et al.[30] also described that "soil erosion was classified and arranged based on slope and vegetation coverage." Consequently, we think that the vegetation coverage and the ground slope are the two most important factors for soil erosion, because in the factors influencing soil erosion, the rain factor acts mainly through the slope steepness and vegetation coverage, the $\mathrm{C}$ factor is controlled mainly by the vegetation coverage, and even the effects of the $\mathrm{P}$ factor follow the changes of slope steepness and vegetation density.

To realize all the above tasks, a series of mathematic modeling and computer simulation are needed. For example, we should establish a relation between vegetation coverage and vegetation index in a so-called reference area by field measurement of vegetation coverage at numerous distributed and accurately positioned quadrates and then extend the relation to a study area by establishing other models. And due to different effects of atmosphere on different image bands, some so-called difference coefficients of atmospheric effects on different bands need to be estimated too.

This new method was originally and experimentally used in a case study area, the Lianshui basin $\left(579.26 \mathrm{~km}^{2}\right)$ of Ganjiang River in Jiangxi Province, China. The results of soil erosion monitoring obtained by this method accorded with those of other scientists obtained by satellite image classification plus visual interpretation [31]. This indicated the feasibility of the method [22,23]. However, the original method was imperfect at that time. Since 
then we have been continuing to improve it. Now all the imperfections in the original version have been corrected greatly. The improved method and its procedures are presented in this paper.

\section{Methodology}

\subsection{Study Area, Instruments and Materials}

The study area is the city of Dandong and its suburbs, Liaoning Province, China $\left(40^{\circ} \mathrm{N}, 125^{\circ} \mathrm{E}\right)$, totaling 909.89 $\mathrm{Km}^{2}$. Its shape looks like a balloon or the map of Brazil (refer to Figure 9). Along the eastern fringe of the area runs the Yalujiang River. The area resembles the conditions of humid temperate zone and is composed of inclining plains and undulating hills. These plains are occupied by agricultural land mainly composed of paddy fields with a very few gently sloping corn farms. The hills are covered by natural temperate forest, shrubs, and grasses. The tree species in the forest are mainly locust, white poplar, maple, oak, pine, China fir, etc. The city of Dandong is on the west bank of the river (the pink area in Figure 9(b)). It must be declared and emphasized here that the study area comprises the Yalujiang River, which is jointly owned by both China and Korea, i.e. some islands belong to Korea and others belong to China. It forms complicated situations and thus none of the maps attached to this paper can be taken formally as the basis of the national boundary between the two countries.

Besides the study area, we have yet a so-called reference area. It is for conducting field measurements to obtain vegetation coverage data and using so-called reference images of ETM+ and SPOT of the area to establish so-called reference relation equations between vegetation coverage and vegetation index values. And in the area, we also used several sets of TM, ETM+ and SPOT images and corresponding atmosphere observation data to make atmospheric corrections with the TURNER model [24] for testing the so-called difference coefficients of atmospheric effects on different image bands, established by the mountain shadow histogram method $[22,23]$. The reference area is located in the city of Nanjing and its surroundings, Jiangsu Province, China $\left(32^{\circ} \mathrm{N}, 119^{\circ} \mathrm{E}\right)$ (refer to Figure 3). It occupies an area of $3024 \mathrm{Km}^{2}$ and is composed of plains and undulating hills, which are scattered with large quantity of small lakes and reservoirs. Through the area run the Yangtze River and its small tributary Qinhuai River. In the center of the area there is the city of Nanjing. Around the city, there is vast land of agricultural crops and bare fields on plains and natural north-subtropical forest, shrubs and grasses on hills. The tree species in the forest are mainly oriental plane (sycamore), locust, poplar, maple, oak, ginkgo, pine, cedar, China fir, etc.
The used instruments in this study comprise: Digital camera, Canon Power Shot G5 (Canon inc. Japan); Star link Invicta 210 DGPS (RAVEN Industries, INC. USA); Digitizer: Size A0; Software: ENVI image processing system; ArcGIS systems (including Arcmap); Microsoft Excel 2003. The used images for the study area: 1) MSS image, Landsat-2, WRS 127-32, Date: 09-15-1976; 2) TM image, Landsat-5, WRS 118-32, Date: 09-12-1989; 3) ETM+ image, Landsat-7, WRS 118-32, Date: 09-212001. The used images for the reference area: 1) TM images: Landsat-5, WRS 120-38, Dates: 07-05-1988 and 10-18-1997; 2) ETM+ images, Landsat-7, WRS 120-38, Dates: $09-16-2000$ and 11-06-2001; 3) SPOT image, SPOT-5, K-J identification 290-286, Date: 11-09-2002. The used topographic maps: for the study area: scale 1:50,000; for the reference area: scales 1:50,000 and $1: 10,000$.

\subsection{A Variable Free from Atmospheric Effects: The Mean Vegetation Coverage Value of the Study Area and Its Estimation}

As the key and first step of the method, we should estimate the mean vegetation coverage value for the whole study area. This value is not affected by atmospheric effects, because it only refers to spatial distribution of vegetation and is always the same in a short period despite transparent or non-transparent atmosphere. Besides the mean vegetation coverage, there are also other variables which are not affected by atmosphere, e.g. the soil erosion amount or other ordinary geographic statistic for an area within or outside the study area [22,23]. However, the mean vegetation coverage value for the study area is preferable, because it can be estimated directly from satellite image itself.

There are several methods for estimating the mean vegetation coverage value. One is the method of visual interpretation. In this case it is enough to only use a color composite of very small scale and hence very small size. Another one is the method of dynamic color composition. This kind of composite is calculated by using the Heckbert Quantization Algorithm [32,33]. We used to apply this kind of composites for determining vegetation coverage values in Lianshui basin, Jiangxi Province, China and found it having a very interesting and surprising function for calculating vegetation coverage. Here we only cite a figure of that research to show the potential of this composite in this respect. Figure 1 shows the histograms of ordinary (or standard) and dynamic color composites.

We can see that the two kinds of histogram are very different: for the standard color composites in different years, there is neither obvious difference in the distribution of image pixels along the gray level axes nor other 

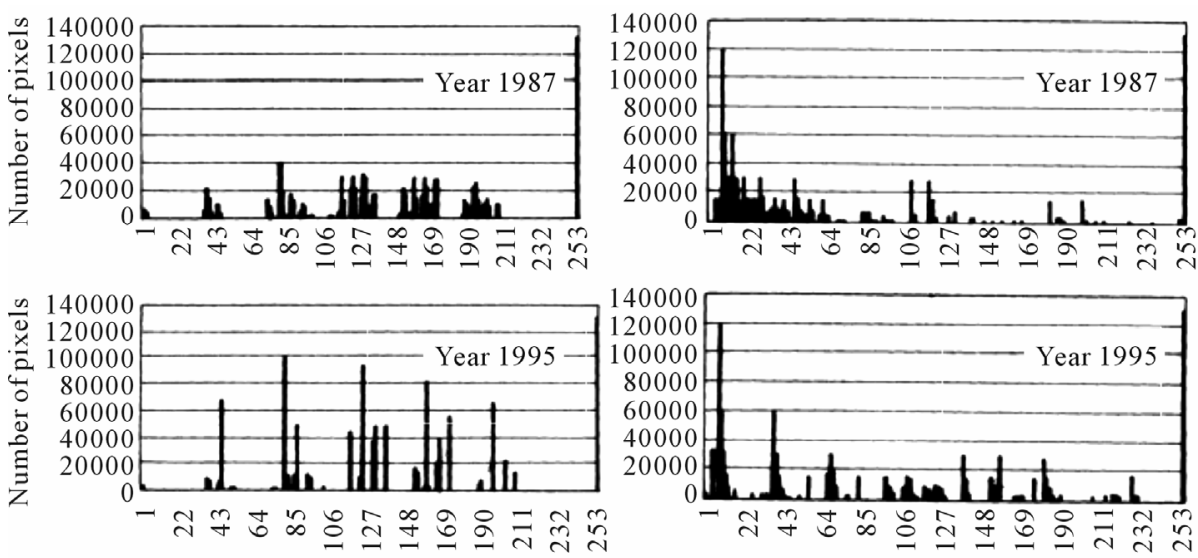

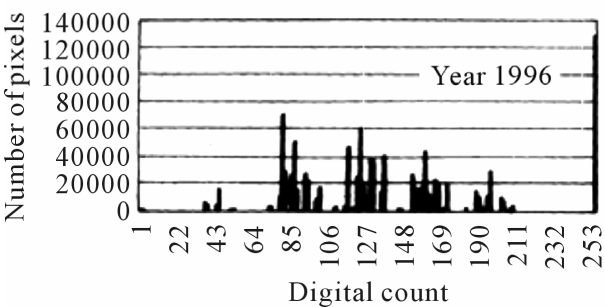

(a)

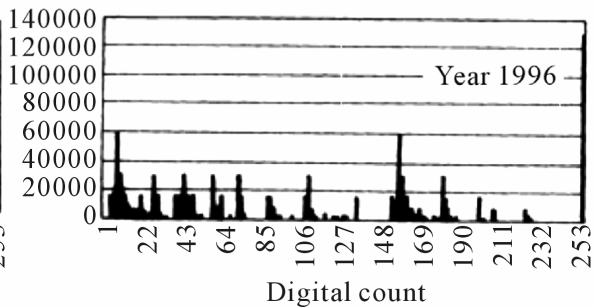

(b)

Figure 1. Comparison of the histograms between the standard color composites (a) and the dynamic color composites (b) for different years in Lianshui basin, Jiangxi Province, China (cited from [23]).

significant difference; but for the dynamic color composites in different years, there is great difference in the distribution of image pixels along the gray level axes: more image pixels concentrated in the range of lower gray level values in 1987 when the vegetation coverage was the lowest (36.83\%); then the more pixels moved towards the direction of higher gray level values in 1995 when the vegetation coverage became greater $(54.87 \%)$; and last, more pixels concentrated in the range of the highest gray level values in 1996 when the vegetation coverage was the highest $(60.71 \%)$. By using some specified threshold values in the histograms or using the average values of gray level, the mean vegetation coverage values of the study area for different years could be obtained and the results are almost the same as those determined by image classifications [23]. The third method is the classification. It is just what we choose of use in this research.

We take the ETM+ image of September 21, 2001 as an example for discussing the estimation. At first we used the ISO data algorithm in ENVI system to conduct an unsupervised classification for the images (geometrically corrected, pixel size $=30 \mathrm{~m} \times 30 \mathrm{~m}$ ). One of the most important classification tactics is to divide the classes as many as possible (20 - 30 classes), because the discrimination of vegetation and non-vegetation is based upon the resulting classes. If the number of classes is too small, then the number of pixels in each class would be big.
This would lead to a discrimination error. We divided the image into 21 classes. Table 1 lists the classification statistics and Figure 2 shows the broken lines of mean gray level values of each class in four classified bands (TM2, 3, 4 and 5).

There are also several methods for differentiating vegetation and non-vegetation according to the classification results, e.g. using the 4-dimensional vegetation index defined by Zeng [23] (refer to the last column of Table 1). However, in this research we only present the method of so-called class broken line analysis and discrimination. Let us look closely at Figure 2. From it we can clearly see that the broken lines of vegetation classes are different from those of other kinds of classes. Classes 1-10 (solid and thick lines) are the dense, very dense, or moderately dense vegetation and their broken lines are prominently concave at the position of TM3 and convex at the position of TM4; classes 13-18 (dotted and thick) are the bare or very bare land and their broken lines are prominently convex at the position of TM3 and concave at the position of TM4, i.e. totally opposite in shape to the dense, very dense, and moderately dense vegetation; classes 19-21 (dotted and thin) are the water bodies and their broken lines are inclined towards right and very low in TM bands 4 and 5; finally classes 11-12 (solid and thin) are the sparse vegetation and their broken lines are just transitional ones between vegetation and bare land, i.e. their lines are almost straight, slightly concave or slightly 
Table 1. Gray level value in four ETM+ bands, NDVI value, 4-dimensional $V_{i}$ value and area value (\%) for the resulting classes of the unsupervised classification in the study area (Dandong, China; ETM+ image of Sep. 21, 2001).

\begin{tabular}{|c|c|c|c|c|c|c|c|c|}
\hline \multirow{2}{*}{$\begin{array}{c}\text { Class No } \\
\text { (NDVI order) }\end{array}$} & \multirow{2}{*}{ Ground feature } & \multirow{2}{*}{ Area\% } & \multicolumn{4}{|c|}{ Mean gray level value for each of the TM bands } & \multirow{2}{*}{$V_{\mathrm{i}}(\mathrm{NDVI})$} & \multirow{2}{*}{$V_{\mathrm{i} 4 \mathrm{~d}}(4$ dimen.) } \\
\hline & & & TM2 & TM3 & TM4 & TM5 & & \\
\hline 1 & Very dense vegetation 1 & 9.8130 & 45.97 & 35.86 & 76.61 & 78.82 & 0.3623 & 87.92 \\
\hline 2 & Very dense vegetation 2 & 6.4509 & 48.91 & 39.34 & 83.81 & 90.68 & 0.3611 & 92.86 \\
\hline 3 & Very dense vegetation 3 & 8.9049 & 43.56 & 33.24 & 67.81 & 67.98 & 0.3421 & 77.71 \\
\hline 4 & Dense vegetation 1 & 8.1539 & 42.21 & 32.63 & 57.20 & 59.36 & 0.2735 & 58.59 \\
\hline 5 & Dense vegetation 2 & 3.9837 & 39.37 & 27.47 & 47.75 & 46.36 & 0.2367 & 55.39 \\
\hline 6 & Dense vegetation 3 & 3.5271 & 62.68 & 55.84 & 88.91 & 75.34 & 0.2285 & 71.51 \\
\hline 7 & Mod. dense vegetation 1 & 8.7268 & 48.26 & 42.39 & 61.74 & 77.45 & 0.1858 & 41.21 \\
\hline 8 & Mod. dense vegetation 2 & 5.9217 & 54.74 & 51.53 & 74.60 & 106.26 & 0.1829 & 40.91 \\
\hline 9 & Mod. dense vegetation 3 & 12.9833 & 52.70 & 49.76 & 67.27 & 89.25 & 0.1496 & 32.20 \\
\hline 10 & Mod. dense vegetation 4 & 4.7148 & 58.43 & 54.70 & 69.11 & 71.33 & 0.1164 & 31.12 \\
\hline 11 & Sparse vegetation 1 & 8.7320 & 60.51 & 62.99 & 68.82 & 97.85 & 0.0442 & 1.67 \\
\hline 12 & Sparse vegetation 2 & 4.9395 & 66.24 & 73.34 & 71.45 & 116.17 & -0.0131 & -21.93 \\
\hline 13 & Bare land 6 & 2.4914 & 69.24 & 75.08 & 53.88 & 80.38 & -0.1644 & -51.01 \\
\hline 14 & Bare land 5 & 2.4113 & 61.97 & 63.35 & 44.29 & 63.85 & -0.1771 & -38.86 \\
\hline 15 & Bare land 4 & 1.5493 & 79.96 & 91.97 & 61.27 & 99.28 & -0.2003 & -79.62 \\
\hline 16 & Bare land 3 & 1.2174 & 91.22 & 110.13 & 71.79 & 127.90 & -0.2108 & -107.18 \\
\hline 17 & Bare land 2 & 1.5600 & 55.64 & 53.04 & 33.91 & 44.88 & -0.2271 & -33.84 \\
\hline 18 & Bare land 1 & 0.4172 & 116.18 & 147.17 & 83.53 & 157.62 & -0.2759 & -174.29 \\
\hline 19 & Water 3 & 1.0787 & 46.51 & 35.20 & 13.81 & 13.34 & -0.4364 & -19.06 \\
\hline 20 & Water 2 & 1.2110 & 56.32 & 55.13 & 20.89 & 15.52 & -0.4504 & -57.47 \\
\hline 21 & Water 1 & 1.2120 & 52.40 & 44.93 & 16.24 & 15.78 & -0.4690 & -38.19 \\
\hline total & & 100.0000 & & & & & & \\
\hline
\end{tabular}

convex at the position of TM3. Consequently, we have ascertained the classes designated by the solid and thick lines, i.e. classes 1-10, as vegetation classes. And then the overall area of the classes 1-10, i.e. $73.18 \%$ (see Table 1) is the estimation of the mean vegetation coverage value for the whole study area for year 2001. Taking the dividing line between the sparse vegetation and the moderately dense vegetation as the limit between vegetation and non-vegetation only possesses correctness statistically, because the classes are statistical ones (classified based on statistical theory), each of them inevitably contains some pixels of other classes. For example, the moderately dense vegetation might contain some pixels of sparse vegetation; contrarily, the sparse vegetation might contain some pixels of moderately dense vegetation. However, this kind of classification errors for the sparse vegetation and the moderately dense vegetation would be mutually compensated or set-off, as an ordinary diagram of two adjacent Normal Distributions can show [34].

We also conducted unsupervised classifications respectively for the MSS image of bands 4, 5, 6, 7 on September 15, 1976 and the TM image of bands 2, 3, 4, 5 on September 12, 1989. The MSS image was classified into 25 classes and the TM image 21 classes. And then following the same procedures as above, we obtained the mean vegetation coverage values of the study area, i.e. $65.62 \%$ for 1976 and $75.07 \%$ for 1989 respectively. For the convenience of the following calculations, we use decimal digits to specify the mean vegetation coverage values $V_{\mathrm{c}}$, i.e. $0.6562,0.7507$ and 0.7318 for 1976,1989 and 2001 respectively. 


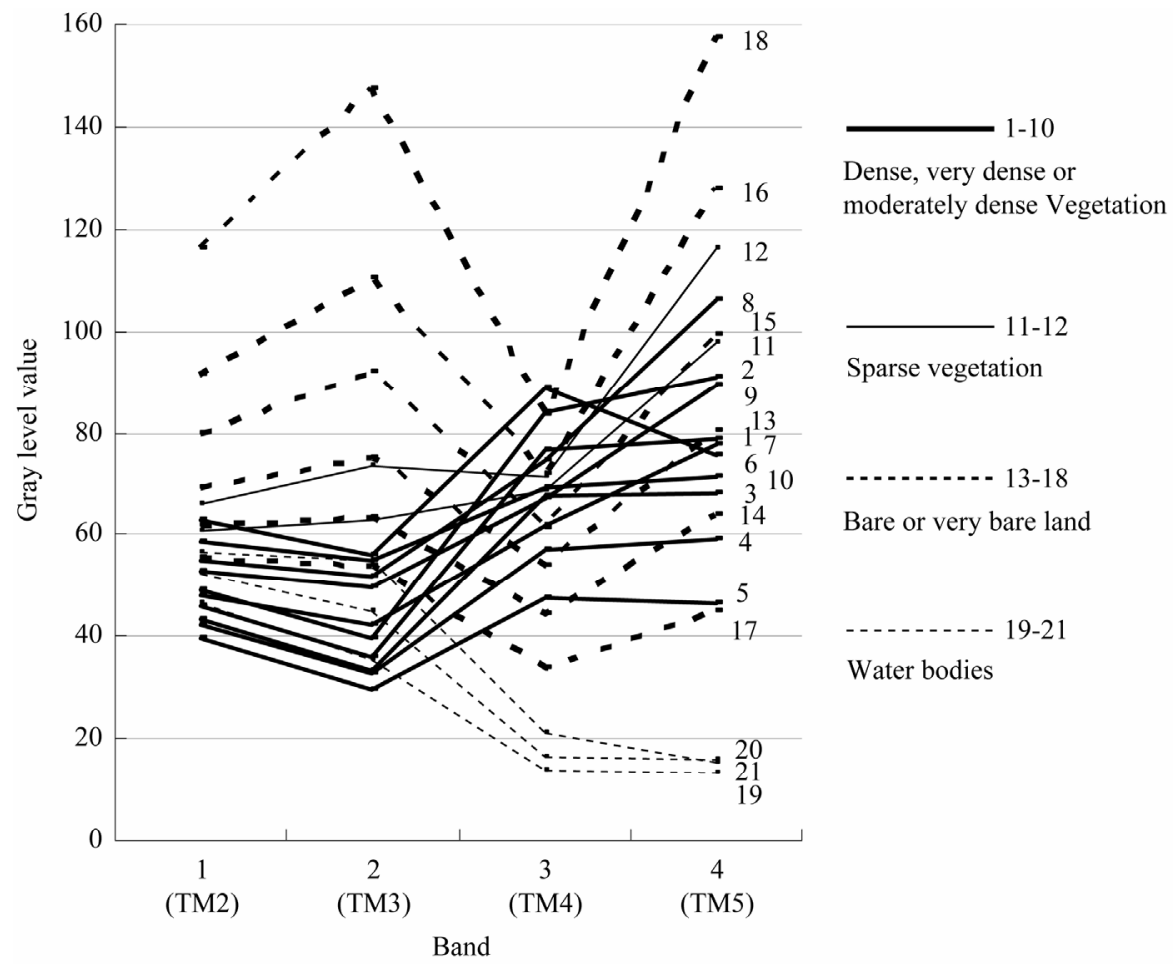

Figure 2. Gray level broken lines of the classes in four ETM+ bands, resulting from an unsupervised classification of ETM+ image of Sep. 21, 2001 in the study area, Dandong, China.

The vegetation coverage value above or other reference variable value here only refers to the mean value of the whole study area and therefore there is only one value for one date's image of the study area and so it is easier to acquire. As for all pixels of the image, vegetation coverage values cannot be obtained like this because the above methods can not reach accuracy at the pixel level. Nevertheless, the mean vegetation coverage value for the whole area obtained like this is a good basis for deducing pixels' vegetation coverage values. How to deduce them on this basis? This is a thorny problem. But obviously, we need to use NDVI value as a bridge, because, just as Drake et al. [12] indicated, "NDVI is currently the only globally available remote sensing estimation of vegetation cover"; Singh et al. (2003) also stated: "NDVI has become the primary tool for mapping changes in vegetation cover".

A series of formulae, models, and simulation calculations are needed. We will talk about them next.

\subsection{Specifying Expressions of NDVI and Other Variables for NDVI Calculation and Atmospheric Correction}

For consistency of calculation, we need to fix the expressions of NDVI and other variables in advance. And for simplification of narration, we use $V_{i}$ to specify the
NDVI. Suppose the atmospheric correctors for TM band 3 and TM band 4 are $c_{3}$ and $c_{4}$ respectively, then we have

$$
\begin{aligned}
V_{\mathrm{i}}= & {\left[\left(T M 4-C_{4}\right)-\left(T M 3-c_{3}\right)\right] / } \\
& {\left[\left(T M 4-C_{4}\right)+\left(T M 3-c_{3}\right)\right] }
\end{aligned}
$$

Or

$$
V_{\mathrm{i}}=(T M 4-T M 3+a) /(T M 4+T M 3+b)
$$

We call $a$ and $b$ numerator corrector and denominator corrector respectively. From Formulae (1) and (2) we know:

$$
\begin{gathered}
a=c_{3}-c_{4} \\
b=-\left(c_{3}+c_{4}\right)
\end{gathered}
$$

Also for convenience of calculation, we define $C$ as the mean corrector for visible band and infrared band, i.e.

$$
C=\left(c_{3}+c_{4}\right) / 2
$$

The $C, c_{3}, c_{4}, a$, and $b$ are the atmospheric correction parameters which we should solve.

\subsection{Estimating the Difference Coefficients of Atmospheric Effects on Different Image Bands}

The $c_{3}$ and $c_{4}$ in Formula (1) are different. This is due to 
differences of atmospheric effects on visible and infrared bands. Tarpley et al. [10] stated briefly: "Atmospheric effects such as scattering by dust and aerosols, Rayleigh scattering and sub pixel-sized clouds all act to increase visible band values with respect to infrared band values and to reduce the computed vegetation indices NDVI". In other conditions, as Townshend et al. [11] pointed out, "reductions in irradiance due to atmospheric effects are higher for shorter wavelengths and thus the NDVI tends to be spuriously increased". These differences mean that we need to consider and estimate the so-called difference coefficients of atmospheric effects on different image bands, which are defined by us as the ratio of a band atmospheric corrector to the mean atmospheric corrector of all the considered bands, i.e.

$$
\begin{aligned}
& k_{3}=c_{3} / C \\
& k_{4}=c_{4} / C
\end{aligned}
$$

The values of $k_{3}$ and $k_{4}$ have been estimated by us in consideration of the variation difference of gray level values of mountain shadows from one year to another in TM bands 3 and 4 . They are respectively: $k_{3}=1.1394, k_{4}$ $=0.8606$ (Zeng, 2001, 2004). In recent years, we have used TM and ETM+ images to conduct more experiments with the $k_{3}$ and $k_{4}$ estimation by the method of mountain shadows histogram in two study areas of Danjiangkou and Baihe, Hubei province, China (four experiments: $k_{3}=1.1575,1.1740,1.0893$, and $1.0840 ; k_{4}=$ $0.8425,0.8260,0.9107$, and 0.9159 ) and also by the atmospheric correction model TURNER in the Nanjing area (four experiments: $k_{3}=1.1842,1.2768,1.2886$, and $1.1264 ; k_{4}=0.8158,0.7232,0.7114$, and 0.8736). The resulting $k_{3}$ and $k_{4}$ values of the two methods are close to each other, proving that both these methods can be used to estimate the difference coefficients $k_{3}$ and $k_{4}$. Hereafter we will adopt the overall average values, i.e. the mean values of the methods of mountain shadows and the TURNER model for further application. They are $k_{3}=$ 1.1783 and $k_{4}=0.8217$, i.e.

$$
\begin{aligned}
& C_{3}=1.1783 C \\
& C_{4}=0.8217 C
\end{aligned}
$$

\subsection{Modeling the Relationship between Vegetation Coverage and Vegetation Index}

The prerequisite of the modeling is having a fair amount of data pairs of vegetation coverage and vegetation index. We used to collect some vegetation coverage data of Xianju County, Zhejiang Province, China, from literature, calculate some corresponding vegetation index values and establish a quadratic regression equation [22,23]. In this study, we did some field measurements in the refer- ence area to get vegetation coverage values. We took the central reference area in Nanjing, China as our measure area (Figure 3) and arranged more than forty measure quadrates (the size is $30 \mathrm{~m} \times 30 \mathrm{~m}$ ) for ETM+ image and over one hundred and forty quadrates (the size is $10 \mathrm{~m} \times$ $10 \mathrm{~m}$ ) for SPOT image. At these quadrates we used Canon Power Shot G5 camera and self-made special stand, hanger rod and hanger cradle to measure the vegetation coverage. Simultaneously, a GPS receiver Starlink Invicta 210 DGPS was used for accurate positioning [35, $36]$. We chose two scenes of images on very clear days for computing corresponding vegetation index values, because the vegetation index values computed from this sort of images are less influenced by atmospheric effects and hence the established vegetation index-coverage relation would be more reliable for reference. Among the images in hand, which were received during the recent 15 years (1989 2004), the reception days of the ETM+ image on November 6, 2001 and the SPOT image on November 9, 2002 have the best atmospheric conditions: the visibility is higher, the atmosphere pressure is higher, the air temperature is lower, the relative humidity is lower and the vapor pressure is lower. So the sky is clear and the weather is excellent; especially at 8 o'clock which is very near the reception hour of images (Table 2). Thus, the two scenes of images were chosen as our reference ones. They were geometrically corrected (the pixel size is $30 \mathrm{~m} \times 30 \mathrm{~m}$ for ETM+ image and $10 \mathrm{~m} \times$ $10 \mathrm{~m}$ for SPOT image).

According to the image reception times, our field measurements of vegetation coverage were all planned to be carried out in the same season (November 1-14, but year 2004). The distribution of sample sites in the reference area is shown in Figure 3. After the measurements,

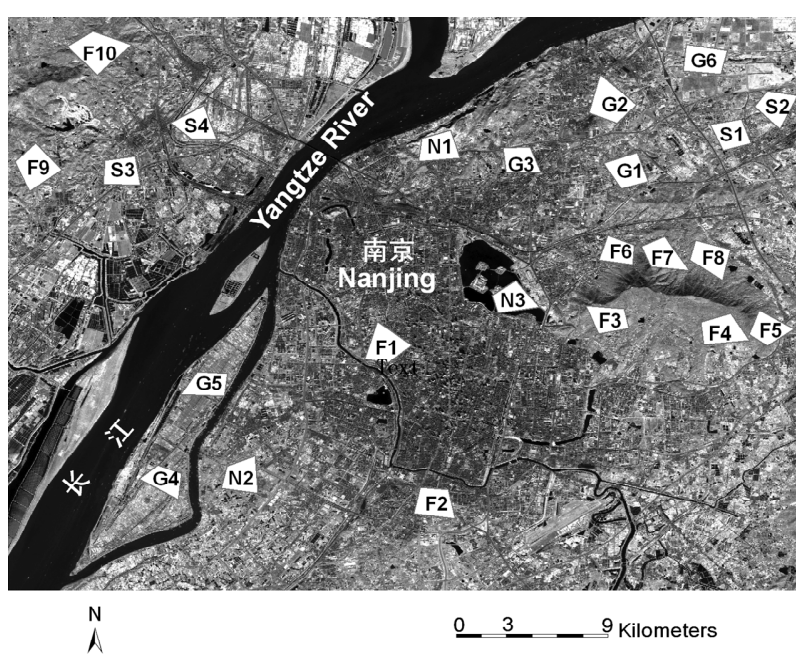

Figure 3. Distribution of the sampling sites in the central reference area: F-Forest sites; S-Shrub sites; G-Grasses sites; N-Non-vegetation sites. 
Table 2. Atmospheric conditions of reception days of some satellite images in the reference area (Nanjing City and its surroundings, China) and in the study area (Dandong City and its suburbs).

\begin{tabular}{|c|c|c|c|c|c|c|}
\hline Date & hour & Visibility, Km & $\begin{array}{c}\text { Barometric } \\
\text { pressure, } 1 \mathrm{mb}\end{array}$ & Air temperature, ${ }^{\circ} \mathrm{C}$ & $\begin{array}{c}\text { Relative } \\
\text { humidity, \% }\end{array}$ & $\begin{array}{c}\text { Vapor pressure, } \\
0.1 \mathrm{mb}\end{array}$ \\
\hline \multicolumn{7}{|l|}{ Reference area } \\
\hline \multirow[t]{2}{*}{$10 / 18 / 1997$} & 8 & 1.5 & 1019.5 & 15.3 & 85 & 14.7 \\
\hline & 14 & 10.0 & 1016.4 & 27.6 & 27 & 9.8 \\
\hline \multirow[t]{2}{*}{$09 / 16 / 2000$} & 8 & 7.0 & 1009.2 & 20.5 & 70 & 16.8 \\
\hline & 14 & 22.0 & 1007.5 & 29.2 & 26 & 10.6 \\
\hline \multirow[t]{2}{*}{$11 / 06 / 2001$} & 8 & 14.0 & 1032.7 & 8.4 & 70 & 2.7 \\
\hline & 14 & 24.0 & 1029.5 & 14.1 & 36 & 5.7 \\
\hline \multirow[t]{2}{*}{$11 / 09 / 2002$} & 8 & 11.0 & 1026.8 & 6.4 & 63 & 6.0 \\
\hline & 14 & 11.0 & 1020.8 & 14.9 & 32 & 5.4 \\
\hline \multicolumn{7}{|l|}{ Study area } \\
\hline \multirow[t]{2}{*}{$09 / 15 / 1976$} & 8 & 6 & 1012.9 & 14.2 & 80 & 13.0 \\
\hline & 14 & 8 & 1010.5 & 23.4 & 37 & 10.6 \\
\hline \multirow[t]{2}{*}{ 09/12/1989 } & 8 & 20 & 1007.9 & 17.2 & 74 & 14.5 \\
\hline & 14 & 25 & 1007.2 & 23.6 & 38 & 11.1 \\
\hline \multirow[t]{2}{*}{$09 / 21 / 2001$} & 8 & 20 & 1028.3 & 12.4 & 30 & 4.3 \\
\hline & 14 & 30 & 1025.3 & 20.0 & 18 & 4.2 \\
\hline
\end{tabular}

we designed a special method for processing photos in laboratory $[35,36]$. Finally, the data pairs of the vegetation index and vegetation coverage for all quadrates were obtained (Table 3, for ETM+ image). Note that the vegetation coverage values equaling 0 (entirely bare land or open water surface) or $1(100 \%$ vegetation cover) were visually determined. We use the data pairs to establish the relation model of vegetation coverage to index by regression analysis. With Microsoft Excel, we established a 4-order polynomial equation as follows and it curve is shown in Figure 4.

$$
\begin{aligned}
V_{\mathrm{c}}= & 6.4870933608640 V_{\mathrm{i}}^{4}-6.172463983663 V_{\mathrm{i}}^{3} \\
& -1.14548311195 \mathrm{~V}_{\mathrm{i}}^{2}+2.3151305575 V_{\mathrm{i}} \\
& +0.492401042 \\
& \left(\mathrm{R}^{2}=0.899607, \text { data pairs }=40\right)
\end{aligned}
$$

The suitability of Equation (10) is in the range of $V_{\mathrm{i}}=$ $-0.22528-0.36572$, i.e. $V_{\mathrm{c}}=0.00000-1.00000$ (in practice) or $V_{\mathrm{i}}=-0.33653-0.42218$, i.e. $V_{\mathrm{c}}=-0.09798$ 1.00726 (theoretically). The foundation of the threshold determination is the first and second derivatives of Equation (10) and its curve in Figure 4. From them we know that The point of $V_{\mathrm{i}}=-0.33653, V_{\mathrm{c}}=-0.09798$ is the minimum of the curve; the point of $V_{\mathrm{i}}=0.42218, V_{\mathrm{c}}=$

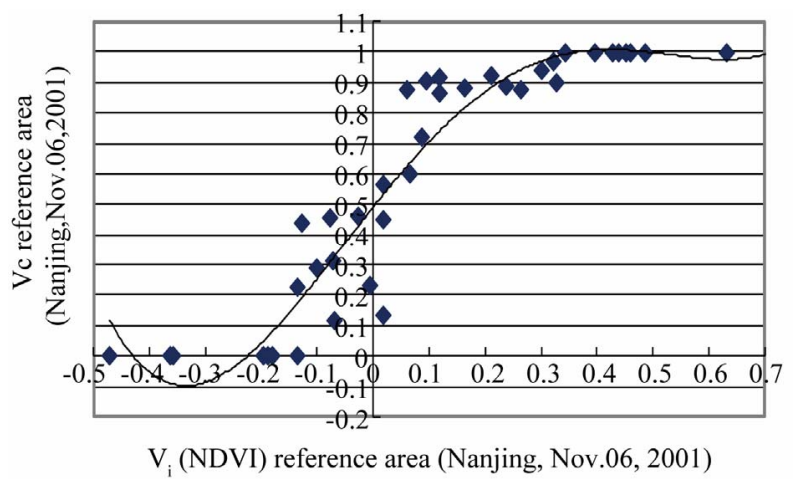

Figure 4. The 4-order polynomial regression curve and its data points of vegetation coverage to vegetation index in the reference area (Nanjing, China), established based on the reference ETM+ image (November 6, 2001).

1.00726 is the significant local maximum of the curve; the point of $V_{\mathrm{i}}=-0.22528$ and $V_{\mathrm{c}}=0.00000$ is the significant intersection point of the curve with the abscissa axis; the point of $V_{\mathrm{i}}=0.36572$ and $V_{\mathrm{c}}=1.00000$ is the significant intersection point of the curve with the line of $V_{\mathrm{c}}=1$; and the the point of $V_{\mathrm{i}}=0.05541$ and $V_{\mathrm{c}}=$ 0.36171 is the significant point of inflexion (indicating speed change of $V_{\mathrm{c}}$ increase with $V_{\mathrm{i}}$ ).

In consequence, we have to only use $V_{\mathrm{i}}=-0.22528$ - 
Table 3. Measured vegetation coverage values and their corresponding vegetation index values in the reference ETM+ image for measurement quadrates of the reference area.

\begin{tabular}{|c|c|c|c|c|c|}
\hline \multirow{2}{*}{$\begin{array}{l}\text { Number of } \\
\text { quadrate }\end{array}$} & \multirow{2}{*}{$\begin{array}{l}\text { Type and status of vegetation } \\
\text { or ground feature }\end{array}$} & \multirow{2}{*}{$\begin{array}{l}\text { Vegetation coverage } \\
\text { value }\left(V_{c}\right)\end{array}$} & \multirow{2}{*}{$\begin{array}{l}\text { Vegetation Index } \\
\text { value }\left(V_{\mathrm{i}}\right)\end{array}$} & \multicolumn{2}{|c|}{ GPS positioning of the quadrate } \\
\hline & & & & Latitude N & Longitude $\mathrm{E}$ \\
\hline 1 & Water (Yangtze river) & 0 & -0.3578 & 32.148551 & 118.797282 \\
\hline 2 & Water (lake) & 0 & -0.3645 & 32.037605 & 118.757994 \\
\hline 3 & Water (lake) & 0 & -0.3636 & 32.073481 & 118.798349 \\
\hline 4 & Water (lake) & 0 & -0.4727 & 32.030171 & 118.822036 \\
\hline 5 & Bare land (buildings) & 0 & -0.1359 & 32.076221 & 118.804170 \\
\hline 6 & Bare land (quarry) & 0 & -0.1880 & 32.137008 & 118.638511 \\
\hline 7 & Bare land (quarry) & 0 & -0.1795 & 32.166730 & 118.869477 \\
\hline 8 & Bare land (cropland) & 0 & -0.1954 & 32.119991 & 118.772371 \\
\hline 9 & Shrubs and grasses & 0.2240 & -0.1356 & 32.021047 & 118.763266 \\
\hline 10 & grasses & 0.4383 & -0.1282 & 32.060442 & 118.745227 \\
\hline 11 & Shrubs and grasses & 0.2885 & -0.1000 & 32.056527 & 118.627621 \\
\hline 12 & grasses & 0.4534 & -0.0787 & 32.058450 & 118.756310 \\
\hline 13 & grasses & 0.3102 & 0.0710 & 31.998201 & 118.668948 \\
\hline 14 & grasses & 0.1152 & -0.0702 & 32.056234 & 118.628194 \\
\hline 15 & Shrubs and grasses & 0.4596 & -0.0278 & 32.175704 & 118.704355 \\
\hline 16 & Shrubs and grasses & 0.2318 & -0.0067 & 32.109713 & 118.905208 \\
\hline 17 & grasses & 0.4514 & 0.0184 & 32.103149 & 118.905983 \\
\hline 18 & grasses & 0.1330 & 0.0184 & 32.103269 & 118.905872 \\
\hline 19 & grasses & 0.5671 & 0.0191 & 32.160044 & 118.783946 \\
\hline 20 & woodland & 0.8778 & 0.0597 & 32.031586 & 118.779283 \\
\hline 21 & woodland & 0.7200 & 0.0862 & 32.048129 & 118.778949 \\
\hline 22 & shrubs & 0.6021 & 0.0651 & 32.108918 & 118.906333 \\
\hline 23 & woodland & 0.9053 & 0.0959 & 32.033218 & 118.704289 \\
\hline 24 & Trees, shrubs and grasses & 0.8676 & 0.1189 & 32.065556 & 118.616573 \\
\hline 25 & Shrubs and grasses & 0.9163 & 0.1189 & 32.065375 & 118.616581 \\
\hline 26 & Trees, shrubs and grasses & 0.8800 & 0.1636 & 32.047871 & 118.825891 \\
\hline 27 & Trees, shrubs and grasses & 0.9206 & 0.2115 & 32.055195 & 118.764950 \\
\hline 28 & Shrubs and grasses & 0.8889 & 0.2389 & 32.050896 & 118.756502 \\
\hline 29 & Shrubs and grasses & 0.8757 & 0.2650 & 32.053248 & 118.755745 \\
\hline 30 & Trees and shrubs & 0.9373 & 0.3000 & 32.051233 & 118.754455 \\
\hline 31 & Trees, shrubs and grasses & 0.9704 & 0.3220 & 32.053147 & 118.825986 \\
\hline 32 & woodland & 0.8980 & 0.3280 & 32.052790 & 118.754499 \\
\hline 33 & Broadleaf forest & 1 & 0.3438 & 32.061181 & 118.835163 \\
\hline 34 & Broadleaf forest & 1 & 0.6324 & 32.064705 & 118.835833 \\
\hline 35 & Broadleaf forest & 1 & 0.4592 & 32.053581 & 118.831353 \\
\hline 36 & Broadleaf forest & 1 & 0.4380 & 32.053166 & 118.827526 \\
\hline 37 & Broadleaf forest & 1 & 0.4530 & 32.053262 & 118.831130 \\
\hline 38 & Broadleaf forest & 1 & 0.3969 & 32.051084 & 118.754309 \\
\hline 39 & Coniferous forest & 1 & 0.4861 & 32.064085 & 118.618000 \\
\hline 40 & Coniferous forest & 1 & 0.4286 & 32.063893 & 118.618269 \\
\hline
\end{tabular}


0.36572 for calculating $V_{\mathrm{c}}\left(V_{\mathrm{c}}=0-1\right)$ in practice. However, theoretically we can also use $V_{\mathrm{i}}=-0.33653$ 0.42218 for calculating $V_{\mathrm{c}}\left(V_{\mathrm{c}}=-0.09798-1.00726\right)$. We call the $V_{\mathrm{i}}=-0.22528-0.36572$ practical thresholds and the $V_{\mathrm{i}}=-0.33653-0.42218$ theoretical thresholds. The significance of the theoretical thresholds is: 1) The water and the bare land can be separated from each other and from other ground features as well in the vegetation coverage map; 2) Part of vegetation coverage values greater than 1 is still reserved, which might indicate better vegetation status than that of $V_{c}=1 ; 3$ ) Beyond these two thresholds, the actually existing data are very few, so only a few values will be cut off and assigned to corresponding threshold values $\left(V_{c}=-0.09798\right.$ or 1.00726$)$.

Using the same procedures, the quantitative relation of vegetation coverage to vegetation index for SPOT image was also figured out based on 144 data pairs. The relation is also a 4-order polynomial equation as follows and its curve is similar to that of TM image (omitted).

$$
\begin{aligned}
V_{\mathrm{c}}= & 2.9052647822973 V_{\mathrm{i}}^{4}-4.355348491887 V_{\mathrm{i}}^{3} \\
& +0.000961875828 V_{\mathrm{i}}^{2}+1.9591288370 V_{\mathrm{i}} \\
& +0.440980513 \\
& \left(\mathrm{R}^{2}=0.663543, \text { data pairs }=144\right)
\end{aligned}
$$

The suitability of Equation (11) is in the range of $V_{\mathrm{i}}=$ $-0.28946-0.37023$, i.e., $V_{\mathrm{c}}=0.00000-1.00000$ in practice or $V_{\mathrm{i}}=-0.33932-0.53497$, i.e., $V_{\mathrm{c}}=-0.01501-$ 1.06048 theoretically.

Equations (10) and (11) can be called reference equations, because they were figured out based on the reference image in the reference area. With these two equations and by using so-called intermediate or transitional equations relating the vegetation index values of the reference images in the reference area (Nanjing City area) to those of other images in other area (e.g., the city of Dandong and its suburbs), new relational equations between vegetation coverage and vegetation index, suitable for the new area, can be obtained.

Generally speaking, for monitoring vegetation and soil erosion change of an area in different periods, it is better to use the same kind of image and the same vegetation coverage-index relation. However, it is not easy for a longer-period monitoring as in our case. The period extended over 25 years from 1976 to 2001; but available to us, for 2001 there was only a scene of ETM+ images, for 1989 only a scene of TM images and for 1976 only MSS images existed. So we have to use different types of image simultaneously and the vegetation coverage-index relation established by ETM+ image for all the years. Nevertheless, the objective of using remote sensing image and related models has been achieved, i.e., to assign or "distribute" correct or rational vegetation coverage values to all pixels and simultaneously keep the mean vegetation coverage value of the study area unchanged (equaling the result of classification). In our study area, the Equation (11) for SPOT image was not used because of lack of SPOT image. However, the equation may be useful to users who have to use SPOT image for their work.

\subsection{Modeling the Relation of Vegetation Index Values of the Reference Area and the Study Area and the Relation of Vegetation Coverage to Vegetation Index in the Study Area}

The relation of vegetation index values of the reference area and the study area is an intermediate or transitional equation for connecting these two areas and popularizing and applying the reference Equation (10) or (11) to the study area or any other new area. In our previous study, we had established a linear equation to do this [22,23]. However, as revealed by recent research, this equation should be a 3 -order polynomial one. We may calculate vegetation index maps or conduct unsupervised classifications of the original images both from the reference area and the study area, respectively, and then seek corresponding data pairs to establish such a kind of regression equation. However, in the two cases, it is necessary to get the reference images of ETM+, Nov. 6, 2001 or SPOT, Nov. 9, 2002 in Nanjing as a reference area. It is not convenient for other users. For simplification, we propose to use a special data set of 12 vegetation index values derived from the Nanjing reference ETM+ images, i.e. the vegetation index values of image minimum, image mean, image maximum, three water bodies, three barest lands, and three densest vegetations.

Using the reference ETM+ images to compute vegetation index map (image) and simultaneously conduct unsupervised classification, we obtained the special data set of 12 values for the reference area: the minimum, mean, and maximum vegetation index values came from the statistics of vegetation index map; the vegetation index values of three water bodies are the three smallest index values in the classified classes; the vegetation index values of three barest lands are the smallest index values except for the water bodies in the classified classes; and the vegetation index values of three dense vegetations are the three greatest index values in the classified classes (Table 4, left column). This special data set can be used to establish the relation of vegetation index values between the reference area and the study area or any other new area. Using the same procedures for the images of all the monitoring years in our study area respectively, we obtained the special data set for each year (in the middle and right columns of Table 4). For any other new 
Table 4. Vegetation index values of 12 special objects for the reference area and the study area.

\begin{tabular}{cccccc}
\hline Special Object & $\begin{array}{c}\text { Reference area Nanjing, } \\
\text { ETM+ Nov. 6, 2001 }\end{array}$ & $\begin{array}{c}\text { Study area Dandong, } \\
\text { MSS Sep. 15, 1976 }\end{array}$ & $\begin{array}{c}\text { Study area Dandong, TM } \\
\text { Sep. 12, 1989 }\end{array}$ & $\begin{array}{c}\text { Study area Dandong, } \\
\text { ETM+ Sep. 21, 2001 }\end{array}$ & $\begin{array}{c}\text { Study area Dandong, } \\
\text { 3-year mean values }\end{array}$ \\
\hline Minimum & -0.9429 & -0.9231 & -0.9630 & -0.9512 & -0.9458 \\
Water 1 (clear \& deep) & -0.3674 & -0.7918 & -0.5495 & -0.4690 & -0.6034 \\
Water 2 (clear \& deep) & -0.3607 & -0.7340 & -0.4319 & -0.4504 & -0.5388 \\
Water 3 (clear \& deep) & -0.2295 & -0.3006 & -0.3470 & -0.4364 & -0.3613 \\
Barest land 1 & -0.1009 & -0.2450 & -0.0617 & -0.2759 & -0.1942 \\
Barest land 2 & -0.0853 & -0.1359 & -0.0483 & -0.2271 & -0.1371 \\
Barest land 3 & -0.0768 & -0.0699 & -0.0481 & -0.2108 & -0.1096 \\
Mean & 0.0690 & 0.4122 & 0.4096 & 0.1492 & 0.3237 \\
Densest vegetation 3 & 0.2972 & 0.5366 & 0.5448 & 0.3421 & 0.4745 \\
Densest vegetation 2 & 0.3176 & 0.5853 & 0.5777 & 0.3611 & 0.5080 \\
Densest vegetation 1 & 0.4336 & 0.6069 & 0.6128 & 0.3623 & 0.5273 \\
Maximum & 0.9310 & 0.8286 & 0.9048 & 0.6441 & 0.7925 \\
\hline
\end{tabular}

area, the 12 special data can be easily obtained too. However, less specific data can also be accepted if it is rather difficult to get 12 data.

By using the corresponding data pairs in Table 4, we can figure out the relational regression equations of the vegetation index values between our study area and the reference area for different years. Generally speaking, the 3 -order polynomial equations fit their data distribution very well. Thus we have

$$
\begin{aligned}
V_{\text {in }}= & 1.30633645564 V_{\mathrm{id} 76}^{3}+0.4111579885 V_{\mathrm{id} 76}^{2} \\
& +0.045059447 V_{\mathrm{id} 76}-0.09233570(\text { year } 1976) \quad(12) \\
& \left(\mathrm{R}^{2}=0.9728528, \text { data pairs }=12\right) \\
V_{\mathrm{in}}= & 0.701896146217 V_{\mathrm{id} 89}^{3}+0.17120203196 V_{\mathrm{id} 89}^{2} \\
& +0.040397816 V_{\mathrm{id} 89}-0.09267900(\text { year } 1989) \quad(13) \\
( & \left.\mathrm{R}^{2}=0.9931883, \text { data pairs }=12\right) \\
V_{\text {in }}= & 0.939256816379 V_{\mathrm{id} 01}^{3}+0.5444966933 V_{\mathrm{id} 01}^{2} \\
& +0.678468076 V_{\text {id } 01}+0.00306898(\text { year } 2001) \quad(14) \\
& \left(\mathrm{R}^{2}=0.9864059, \text { data pairs }=12\right) \\
V_{\text {in }}= & 0.976796657728 V_{\text {idmean }}^{3}+0.3315327055 V_{\text {idmean }}^{2} \\
& +0.378820538 V_{\text {idmean }}-0.061165112(3-\text { year mean }) \\
( & \left(\mathrm{R}^{2}=0.9949500, \text { data pairs }=12\right)
\end{aligned}
$$

In the equations above, $V_{\mathrm{in}}, V_{\mathrm{id} 76}, V_{\mathrm{id} 89}, V_{\mathrm{id} 01}$, and $V_{\text {idmean }}$ are the NDVI values respectively for year 2001 of
Nanjing as the reference area and for years 1976, 1989, 2001, and the 3-year average of Dandong as the study area. Figure 5 shows the curves of Equations (12)-(14) only.

The next we would like to talk about is the relationship of vegetation coverage to vegetation index in the study area. Theoretically, we might substitute $V_{\text {in }}$ of Equations (12)-(14) respectively for Equation (10) to obtain the relational equations. But in this case we will obtain three 7-order polynomial equations. The reduction will be a bit troublesome. In addition, the 7-order is too high so that the calculated values would be greatly varying and hence erroneous at the two ends of the curve. By making appropriate adaptation, we suppose the mean vegetation index values of the study area $V_{\text {id }}$ to be, for example, $-0.7,-0.6, \cdots, 0, \cdots, 0.6,0.7$ and substitute these $V_{\mathrm{id}}$ values for Equations (12)-(14) respectively to obtain the corresponding vegetation index values $V_{\text {in }}$. Then, by substituting the $V_{\text {in }}$ values for Equation (10), we will obtain the corresponding vegetation coverage $V_{\mathrm{c}}$ values. Finally, we use the data pairs of $V_{\text {id }}$ and $V_{\mathrm{c}}$ to structure regression equations, which will be the relational equations of vegetation coverage to vegetation index for the study area. As an example, Table 5 lists the corresponding values for year 1976. Its relational equation is a 5-order polynomial one as follows:

$$
\begin{aligned}
V_{\mathrm{c}}= & -6.1542529667859 V_{\mathrm{d} 76}^{5}-1.851770749887 V_{\mathrm{d} 76}^{4} \\
& +4.50069636461 V_{\mathrm{d} 76}^{3}+1.2666003772 V_{\mathrm{d} 76}^{2} \\
& +0.035544188 V_{\mathrm{d} 76}+0.26889446
\end{aligned}
$$

Figure 6 shows its curve. It should be noted that Equa- 


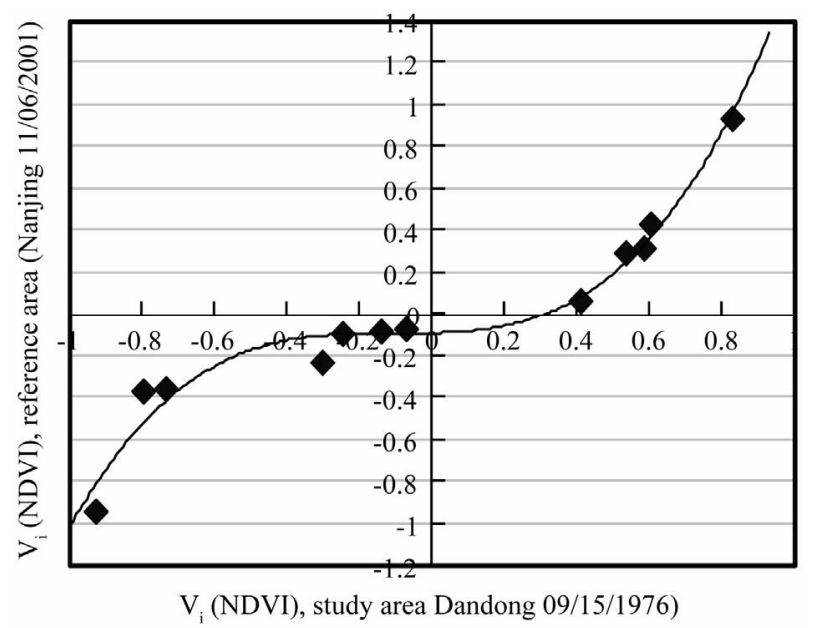

(a)

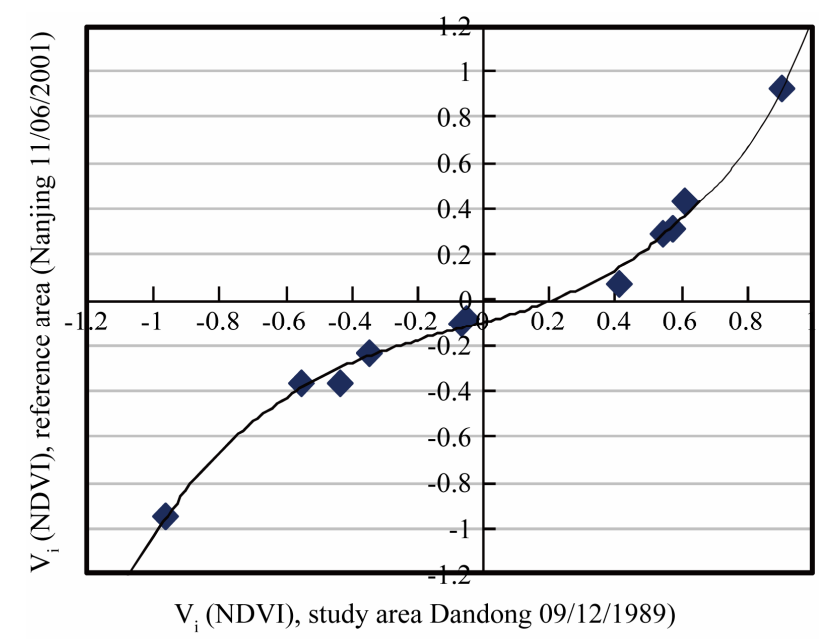

(b)

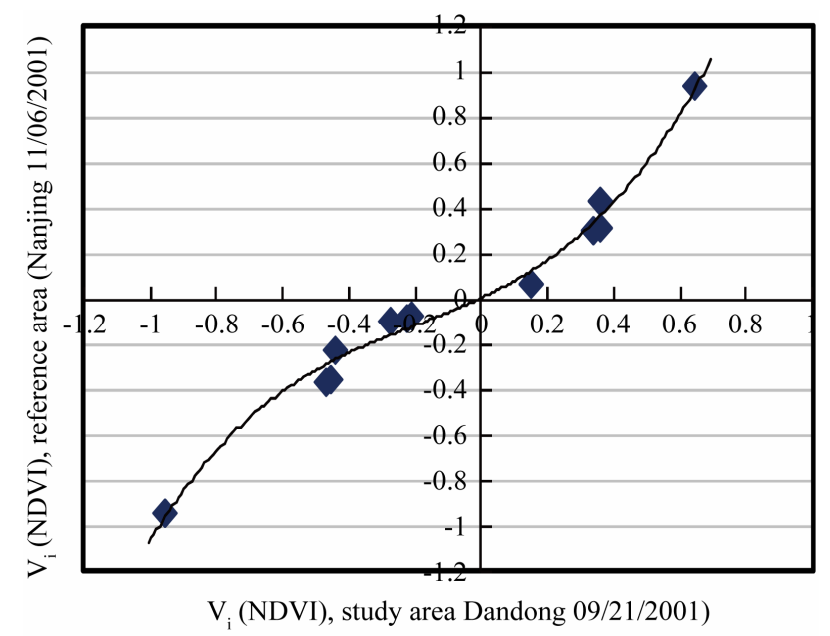

(c)

Figure 5. Curves of the regression equations of the vegetation index values between the study area and the reference area for different monitoring years: (a) 1976; (b) 1989; (c) 2001.
Table 5. Vegetation index values of the study area (supposed), vegetation index values of the reference area (calculated by Equation (12)) and vegetation coverage values (calculated by Equation (10)) for the year 1976.

\begin{tabular}{ccc}
\hline $\begin{array}{c}\text { Vegetation index for } \\
\text { study area, } V_{\text {id76 }}\end{array}$ & $\begin{array}{c}\text { Vegetation index for } \\
\text { reference area, } V_{\text {in }}\end{array}$ & $\begin{array}{c}\text { Vegetation } \\
\text { coverage, } V_{\mathrm{c} 76}\end{array}$ \\
\hline-0.7 & -0.370483 & -0.086447 \\
-0.6 & -0.253523 & -0.040784 \\
-0.5 & -0.175368 & 0.090598 \\
-0.4 & -0.128180 & 0.191578 \\
-0.3 & -0.104120 & 0.246661 \\
-0.2 & -0.095352 & 0.267121 \\
-0.1 & -0.094036 & 0.270206 \\
0 & -0.092336 & 0.274196 \\
0.1 & -0.082412 & 0.297581 \\
0.2 & -0.056427 & 0.359293 \\
0.3 & -0.006543 & 0.477206 \\
0.4 & 0.075079 & 0.657356 \\
0.5 & 0.196276 & 0.865632 \\
0.6 & 0.364886 & 0.999775 \\
0.7 & 0.588774 & 0.978150 \\
\hline
\end{tabular}

tion (16) and also the upcoming Equations (17) and (18) were all structured by regression method in form but mathematically in fact, because the data for structuring these equations were all mathematically calculated by Equations (12)-(14) and (10), respectively, and all the equations are fixed when being used, despite of their original regression property. Therefore, the correlation coefficients of Equations (16)-(18) are insignificant and not listed (the values of their correlation coefficients are nearly 1.0), even though these equations are still used as regression ones.

Theoretically, the suitability of Equation (16) is in the range of $V_{\mathrm{id} 76}=-0.70204-0.64380$, i.e. $V_{\mathrm{c}}=-0.089387$ - 1.018948 (the lowest and the highest points of the curve in Figure 6). But in practical use, the suitable $V_{\text {id76 values }}$ should be $-0.57134-0.60024$, i.e. $V_{c}=0.00000$ 1.00000 .

Following the same procedures, the vegetation coverage-index relation equations for 1989 and 2001 were also figured out. They are respectively shown as follows:

$$
\begin{aligned}
V_{\mathrm{c}}= & -4.3147127293742 V_{\mathrm{d} 89}^{5}+0.563786633935 V_{\mathrm{d} 89}^{4} \\
& +1.26514392638 V_{\mathrm{d} 89}^{3}+0.4048724515 V_{\mathrm{d} 89}^{2} \\
& +0.958111039 V_{\mathrm{d} 89}+0.27715437
\end{aligned}
$$




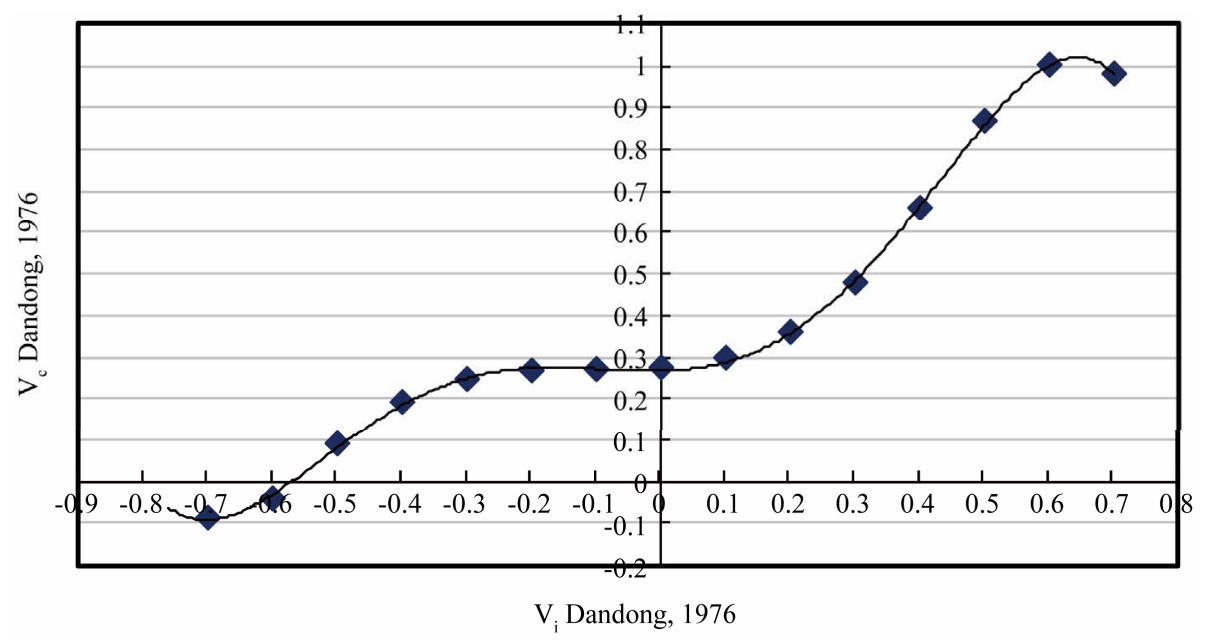

Figure 6. Curve of Equation (16), i.e., the relation of vegetation coverage values to vegetation index values for the year of 1976 in the study area. The curve resembles a dinosaur exactly in shape.

$$
\begin{aligned}
V_{\mathrm{c}}= & -5.4393797134035 V_{\mathrm{d} 01}^{5}-2.089316082194 V_{\mathrm{d} 01}^{4} \\
& -0.58740252658 V_{\mathrm{d} 01}^{3}+0.2717343989 V_{\mathrm{d} 01}^{2} \\
& +1.543977377 V_{\mathrm{d} 01}+0.50666771
\end{aligned}
$$

The suitability of Equation (17) is in the range of $V_{\mathrm{i}}=$ $-0.48584-0.64019$, i.e. $V_{c}=-0.089647$ (minimum) 1.019130 (maximum) theoretically or in the range of $V_{\mathrm{i}}=$ $-0.30866-0.58515$, i.e. $V_{c}=0.00000-1.00000$ in practice. The suitability of Equation (18) is in the range of $V_{\mathrm{i}}$ $=-0.51736-0.41970$, i.e. $V_{\mathrm{c}}=-0.096123$ (minimum) 1.023452 (maximum) theoretically or in the range of $V_{\mathrm{i}}=$ $-0.37090-0.35658$, i.e. $V_{\mathrm{c}}=0.00000-1.00000$ in practice. Equations (16)-(18) can be called synthesized onestep equations.

\subsection{Simulation Calculations, Atmospheric Corrections and Monitoring of Vegetation and Soil Erosion}

The following work is conducting a series of simulation calculations and hence finding out relations of atmospheric correction parameters to vegetation index increments, and solving the due atmospheric correction parameters. After that, the atmospheric correction for images can be carried out, the correct vegetation index and coverage values for all pixels and their maps can be calculated and then the plant cover and soil erosion monitoring can be realized.

\section{Results and Discussions}

\subsection{Simulation Results and Discussions}

At the very beginning of simulation, we supposed a series of the mean corrector $C$ values and then use Formulae (8), (9), (3) and (4) respectively to get the corre- sponding band correctors $c_{3}, c_{4}$ values and the numerator and denominator correctors $a, b$ values. Next, we use the Formula (2) to simultaneously calculate vegetation index values and conduct atmospheric corrections. As for converting the vegetation index values of the study area to those of the reference area and calculating the vegetation coverage values from the converted vegetation index values, we can use the synthesized one-step Equations (16)-(18) or the two-step equations, i.e. use Equations (12)-(14) first and then use Equation (10). Here, we used the two-steps equations first. We take the ETM+ image of Sept. 21, 2001 as an example to show the procedures of simulation calculations in ENVI processing system (please refer to Appendix also):

1) By taking the $a$ and $b$ values when $C=-2,-1,0,1$, 2,3 (one can estimate or try what and how many values of $C$ should be used) and using Formula (2) to calculate the vegetation index values in 2001, obtaining the atmospherically corrected vegetation index values $V_{\mathrm{id} 01}$ and their maps. Note that when $C=0$, then $a=0$ and $b=0$, the $V_{\mathrm{id} 01}$ values and their map are the atmospherically uncorrected values and their map. We indicated the latter $V_{\text {id010. }}$.

2) By using Equation (12), we obtained the vegetation index $V_{\text {in }}$ values and their maps, named $V_{\text {id01n }}$.

3) Using the threshold values $V_{\mathrm{i}}=-0.22528-0.36572$ of the reference Equation (10) to cut off the too small and too great $V_{\mathrm{id} 01 \mathrm{n}}$ values of the maps, making their vegetation coverage values in the range of $0-1$. Thus we obtained the cut vegetation index values and their maps $V_{\text {idolncut. }}$

4) By using Equation (10), we obtained correct vegetation coverage values and their maps, named $V_{\text {cd01ncut }}$, but for convenience, simply named $V_{\text {cd01 }}$.

After each of the simulative calculations, the histo- 
gram for each resulting map should be calculated to get necessary statistics, especially their mean values for the whole study area. Through the simulative calculations, we have finally obtained a series of simulated values and maps of $V_{\mathrm{id} 01}, V_{\mathrm{id} 01 \mathrm{n}}, V_{\mathrm{id} 01 \text { ncut }}$, and $V_{\mathrm{cd} 01}$. Then the vegetation index increment values $\Delta V_{\text {id } 01}$ can also be calculated by the following formula in general:

$$
\Delta V_{\mathrm{i}}=V_{\mathrm{i}}-V_{\mathrm{i} 0}
$$

In the formula, the $V_{\mathrm{i}}$ value which derived from the simulation process is regarded by us as the atmospherically corrected mean vegetation index value and the $V_{\mathrm{i} 0}$ is the $V_{\mathrm{i}}$ value when $C=0$, i.e. the atmospherically uncorrected mean vegetation index value for the study area. The $V_{\mathrm{id} 010}=0.149239$ (see Table 6). From Formula (19), we know that $\Delta V_{\mathrm{id} 01}=V_{\mathrm{id01}}-0.149239$ for the image of 2001. In Table 6, we only listed the simulated average values for the whole study area. Obviously the magnitude of $\Delta V_{\mathrm{i}}$ reflects the extent of atmospheric effects and theoretically we can deduce the atmospheric correction parameter from the $\Delta V_{\mathrm{i}}$.

Using the same procedures and supposing $C=0,-1$, $-2,-3,-4,-5,-6$ and $C=-1,-2,-3,-4,-5,-6,-7$ respectively, the simulative calculations for 1976 and 1989 can be also carried out and their simulated values and maps of $V_{\mathrm{id76}}, V_{\mathrm{id76n}}, V_{\mathrm{id76ncut}}, \Delta V_{\mathrm{id76}}, V_{\mathrm{cd} 76}$ and $V_{\mathrm{id} 89}$, $V_{\text {id89n }}, V_{\text {id89ncut }}, \Delta V_{\text {id89 }}, V_{\text {cd89 }}$ can be also obtained (not listed). It is necessary to mention that for the MSS image of 1976, we used formula $V_{\text {id76 }}=($ MSS7 - MSS5 $+a) /$ $(M S S 7+M S S 5+b)$ instead of formula (2).

Based on the simulation data pairs in Table 6, we figured out the following 2-order polynomial regression equations for the year of 2001:

$$
\begin{aligned}
V_{\mathrm{id} 01}= & 3.904254511 V_{\mathrm{cd} 01}^{2}-4.716306472 V_{\mathrm{cd} 01} \\
& +1.515224738 \\
C= & -507.888822182\left(\Delta V_{\mathrm{id} 01}\right)^{2} \\
+ & 171.581092015\left(\Delta V_{\mathrm{id} 01}\right)-0.00092770624
\end{aligned}
$$

$$
\begin{aligned}
C= & 170.498222689 V_{\mathrm{cd} 01}^{2}-84.4882934484 V_{\mathrm{cd} 01} \\
& -28.5622567074
\end{aligned}
$$

Note that all these equations are regression equations in form but almost mathematical equations in fact, because they were figured out based on the data calculated by corresponding equations in simulation. Therefore, the correlation coefficients of the Equations (20)-(22) are insignificant and not listed (the values of their correlation coefficients are nearly 1.0). The equation curves almost pass through all data points exactly, as Figure 7 shows. Among the equations above, equation (21) is the so-called relation model of the atmospheric correction parameter $C$ to the vegetation index increment $\Delta V_{\text {id } 01}$.

Similarly, from the supposed $C$ values and corresponding simulated data pairs for 1976 and 1989 (not listed), we can also figure out the equations $V_{\mathrm{id}}=f\left(V_{\mathrm{cd}}\right)$, $C=f\left(\Delta V_{\text {id }}\right)$ and $C=f\left(V_{\text {cd }}\right)$ for the years 1976 and 1989 respectively:

$$
\begin{aligned}
V_{\mathrm{id} 76}= & 0.0274492004137 V_{\mathrm{cd} 76}^{2}+0.486040822116 V_{\mathrm{cd} 76} \\
& +0.02948636616 \\
C= & -99.352058245426\left(\Delta V_{\mathrm{id} 76}\right)^{2} \\
+ & 49.91418527998\left(\Delta V_{\mathrm{id} 76}\right)-0.006786698882 \\
C= & -25.9571404450 V_{\mathrm{cd} 76}^{2}+65.4992299763 V_{\mathrm{cd} 76} \\
& -34.6714775372 \\
V_{\mathrm{id} 89}= & 1.082756416921 V_{\mathrm{cd} 89}^{2}-0.843257649618 V_{\mathrm{cd} 89} \\
& +0.3920659730 \\
C=- & 177.50226229782\left(\Delta V_{\mathrm{id} 89}\right)^{2} \\
+ & 84.50953626216\left(\Delta V_{\mathrm{id} 89}\right)-0.00354815378 \\
C= & -5.98406989513 V_{\mathrm{cd} 89}^{2}+85.8549667258 V_{\mathrm{cd} 89} \\
& -64.7786479540
\end{aligned}
$$

\begin{tabular}{|c|c|c|c|c|c|c|c|}
\hline$C$ & $\begin{array}{l}\text { Numerator } \\
\text { corrector } a\end{array}$ & $\begin{array}{l}\text { Denominator } \\
\text { corrector } b\end{array}$ & $V_{\mathrm{id} 01}$ & $V_{\mathrm{id} 01 \mathrm{n}}$ & $V_{\text {id01ncut }}$ & $\Delta V_{\mathrm{id} 01}$ & $V_{\mathrm{cd} 01}$ \\
\hline-2 & -0.7312 & 4.0000 & 0.137970 & 0.138875 & 0.135788 & -0.011269 & 0.713806 \\
\hline-1 & -0.3566 & 2.0000 & 0.143506 & 0.145415 & 0.141063 & -0.005733 & 0.720033 \\
\hline 0 & 0.0000 & 0.0000 & $0.149239^{*}$ & 0.152318 & 0.146374 & 0.000000 & 0.726208 \\
\hline 1 & 0.3566 & -2.0000 & 0.155181 & 0.159615 & 0.151693 & 0.005942 & 0.732315 \\
\hline 2 & 0.7312 & -4.0000 & 0.161343 & 0.167337 & 0.156989 & 0.012104 & 0.738335 \\
\hline 3 & 1.0698 & -6.0000 & 0.167736 & 0.175523 & 0.162236 & 0.018497 & 0.744254 \\
\hline
\end{tabular}

Similarly, the correlation coefficients of Equations

Table 6. The supposed mean correctors $C$, the simulative area-averaged values of the corrected vegetation index, the converted vegetation index, the cut converted vegetation index, the vegetation index increment, and the vegetation coverage for the study area, i.e., the $V_{\mathrm{id} 01}, V_{\mathrm{id} 01 \mathrm{n}}, V_{\mathrm{id} 01 \mathrm{ncut}}, \Delta V_{\mathrm{id} 01}$, and $V_{\mathrm{cd} 01}$ (year 2001 and each-year model \& two-step procedure). 


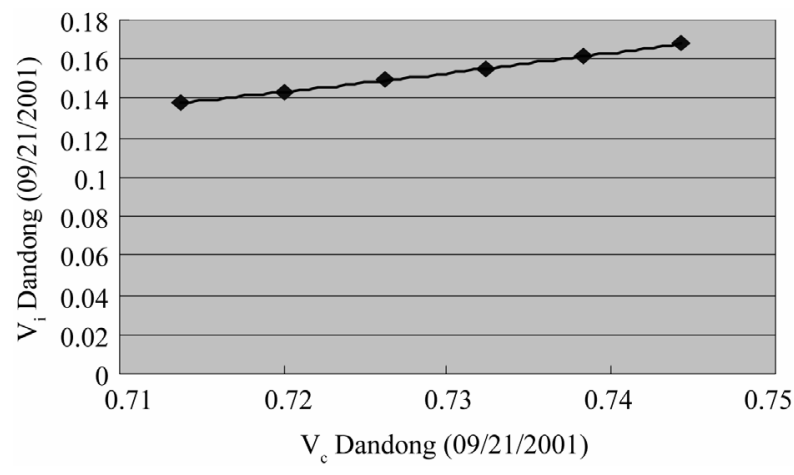

(a)

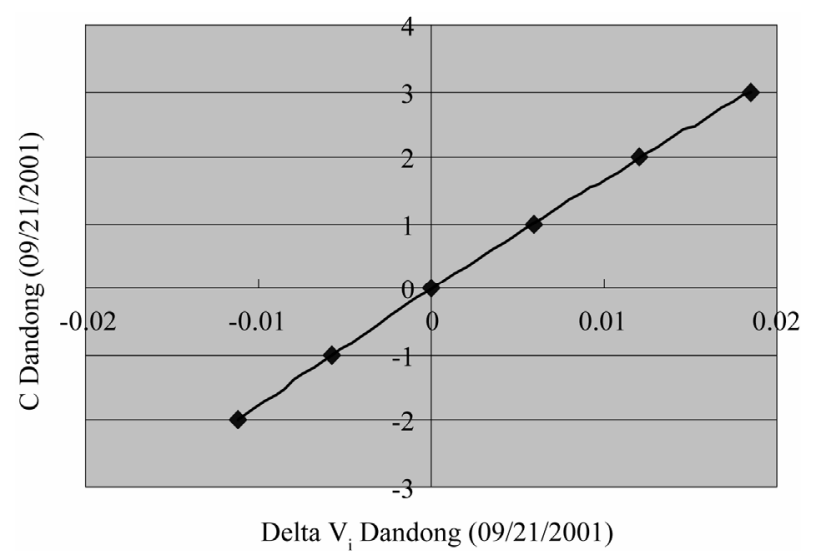

(b)

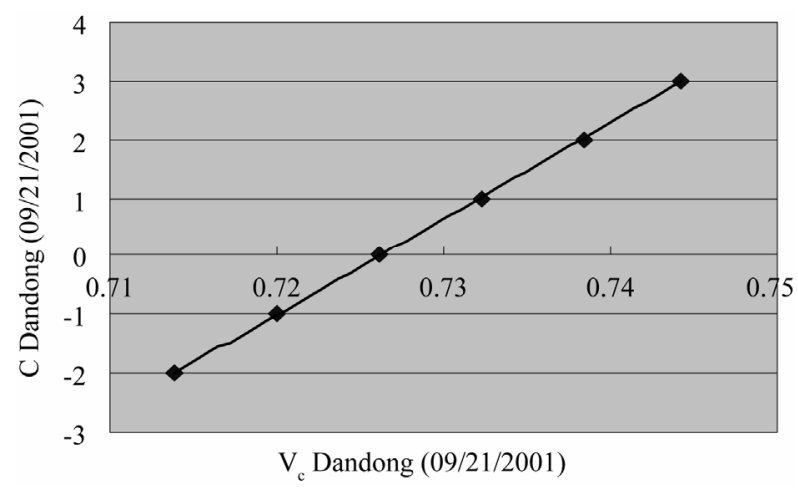

(c)

Figure 7. Curves of some relation equations for the year 2001 in the study area: (a) the mean vegetation index $V_{i}$ with the mean vegetation coverage $V_{c}$; (b) the mean atmospheric corrector $C$ with the mean vegetation index increment $\Delta V_{i}$ of the atmospherically corrected to the uncorrected, and (c) the mean atmospheric corrector $C$ with the mean vegetation coverage $V_{\mathrm{c}}$.

(23)-(28) are insignificant and not listed (nearly equaling 1).

For year 2001, the mean vegetation coverage $V_{\text {cd01 }}$ of the whole study area from the classification was 0.7318 . Substituting 0.73180000 (0.7318 is regarded as correct value) for $V_{\mathrm{cd} 01}$ of Equation (20), we obtained the $V_{\mathrm{id01}}$, i.e. the so-called correct or atmospherically unaffected mean vegetation index value of the study area in 2001 , which equals 0.15468192 (we should reserve enough decimals in the simulation calculations in order to ensure the ultimate precision). However, the original or the atmospherically affected mean vegetation index value $V_{\text {id } 010}=0.14923900$ (also regarded as the correct value), so the increment value of the atmospherically unaffected mean vegetation index to the atmospherically affected mean vegetation index $\Delta V_{\mathrm{id} 01}=0.00544292$.

It is the $\Delta V_{\mathrm{id} 01}$ that is an indicator of the extent of atmospheric effects. From Equation (21) we know that the greater the $\Delta V_{\mathrm{id} 01}$, the greater the mean atmospheric corrector $C$, and the greater the atmospheric effect. By substituting $\Delta V_{\mathrm{id} 01}=0.00544292$ for Equation (21), we obtained the mean corrector $C=0.91792822$.

The paragraphs above have theoretically explained the mechanism of atmospheric influence and the pathway of its correction. However, in practice, it is better to directly use Equation (22) to obtain the $C$ value from $V_{\text {cd01 }}$ because of more simplification and more precision in onestep calculation. Substituting $V_{\text {cd01 }}=0.73180000$ for Equation (22), we got $C=0.91633473$. The confirmation rate of it to $C=0.91792822$ is $99.83 \%$. However, 0.91633473 is more accurate. We adopted $C=$ 0.91633473 . Thus $c_{3}=1.07971721, c_{4}=0.75295225, a=$ 0.32676496 , and $b=-1.83266946$.

Similarly, we can also obtain the atmospheric correction parameters for years 1976 and 1989. For year 1976, by substituting $V_{\text {cd76 }}=0.65620000$ for Equation (25), we obtained $C=-2.86798697, c_{3}=-3.37934904, c_{4}=$ $-2.35662489, a=-1.02272415$, and $b=5.73597393$. For year 1989 , by substituting $V_{\mathrm{cd} 89}=0.75070000$ for Equation (28), we obtained $C=-3.69964996, \quad c_{3}=$ $-4.35929755, c_{4}=-3.04000237, a=-1.31929518$, and $b$ $=7.39929992$.

Up to this step, all the atmospheric correction parameters for different years have been estimated.

Note that until now, the values which we have been seeking for are merely the mean values for the whole study area. That is to say, for one variable of one date or one year, only one value is needed. However, in the following steps, the values which we will be seeking for and dealing with are those for millions upon millions of pixels in the study area. Note that the difference of atmospheric effects within a scene of image is left out of consideration, because it is negligible.

\subsection{Atmospheric Correction Results and Discussions}

Still take the ETM+ image of Sept. 21, 2001 as an example. For simplification, we had better to directly use the 
resulting numerator and denominator correctors $a$ and $b$ to simultaneously correct images and calculate the vegetation index values and then calculate the vegetation coverage values. By substituting the TM3 image, TM4 image and $a=0.32366496, b=-1.83266946$ into formula (2) to conduct so-called map calculation, the corrected vegetation index values and their map $V_{\text {id01 }}$ were obtained. By substituting the map $V_{\mathrm{id} 01}$ in Equation (14), we obtained the corrected vegetation index values and their map $V_{\text {ind01 }}$. Then using the threshold values of Equation (10), i.e. $V_{\mathrm{i}}=-0.22528-0.36572$ to cut the too small and too big values in the $V_{\text {ind01 }}$ map for making the calculated vegetation coverage values in the range of $0 \sim$ 1. Thus we obtained the cut vegetation index values and their map $V_{\text {indolcut. }}$ The histogram of the map shows its mean vegetation index value $V_{\text {ind01cut }}=0.151248$ for the study area. By substituting $V_{\text {indolcut }}$ map for $V_{\mathrm{i}}$ in equation (10), the corrected vegetation coverage values and their map $V_{\text {cd01 }}$ were generated. The histogram of the map shows its mean vegetation coverage value $V_{\text {cd01 }}=$ 0.731807 for the whole study area, which exactly equals that of the classification result (0.7318). Thereupon, we have seen that the anticipated aim of correcting images and assigning or "distributing" rational vegetation coverage values to all pixels of the study area has been achieved.

Following the same procedures, we corrected the TM image of 1989 and the MSS image of 1976. For the image of 1989, we used $a=-1.31929518, b=7.39929992$, and Equation (13); for the image of 1976, we used $a=$ $-1.02272415, b=5.73597393$, and Equation (12). We obtained their corrected vegetation index and coverage values for all pixels and the resulting maps. The mean values for the study area are respectively: $V_{\text {ind89cut }}=$ $0.145083, V_{\text {cd89 }}=0.750659, V_{\text {ind76cut }}=0.086276$, and $V_{\mathrm{cd} 76}=0.656149$. The pixels-statistical mean vegetation coverage values equal those of the classification results.

Besides the above algorithm (including the model and procedure), we have also tried some other algorithms. We summarized them as follows.

Algorithm (1): Each-year model \& two-step procedure, i.e. the algorithm described as above and just what we used as an example.

Algorithm (2): Each-year model \& one-step procedure, i.e. using the synthesized one-step Equations (16)-(18) to directly convert the vegetation index values of the study area into the vegetation coverage values.

Algorithm (3): 3-year-mean model \& two-step procedure, i.e. using Equations (15) and (10) for calculation.

Algorithm (4): One-year model \& one-step procedure, i.e. only using a selected synthesized one-step equation of the years 1976, 1989 or 2001, i.e., Equations (16)-(18), e.g. the Equation (18) of 2001, for all years.
Algorithm (5): no-transition model \& one-step procedure, i.e., directly using Equation (10) to convert the vegetation index values of the study area to vegetation coverage values for all years.

Algorithm (6): 3-order model \& two-step procedure. The 3-order model was established by the data pairs in Table 3 except for those of water bodies and some other features:

$$
\begin{aligned}
V_{\mathrm{c}}= & 0.502854541 V_{\mathrm{i}}^{3}-2.76061717 V_{\mathrm{i}}^{2} \\
& +2.2449857 V_{\mathrm{i}}+0.512250579 \\
& \left(\mathrm{R}^{2}=0.87365287, \text { data pairs }=37\right)
\end{aligned}
$$

Algorithm (7): 2-order model \& two-step procedure. The 2-order model was also established by the data pairs in Table 3 except for those of water bodies and some other features:

$$
\begin{gathered}
V_{\mathrm{c}}=-2.4723283 V_{\mathrm{i}}^{2}+2.2384756 V_{\mathrm{i}}+0.5065307 \\
\quad\left(\mathrm{R}^{2}=0.8733798, \text { data pairs }=37\right)
\end{gathered}
$$

Algorithm (8): no-error model \& two-step procedure. The no error-model is what was established by deleting some data pairs in Table 3 to make its calculated mean vegetation coverage value for the reference area equaling the classification-determined value for the area:

$$
\begin{aligned}
& V_{\mathrm{c}}= 2.4094382749 V_{\mathrm{i}}^{4}-5.053033459 V_{\mathrm{i}}^{3} \\
&+0.38973559 V_{\mathrm{i}}^{2}+2.1073472 V_{\mathrm{i}}+0.3578157 \\
&\left(\mathrm{R}^{2}=0.95632924, \text { data pairs }=26\right)
\end{aligned}
$$

The results derived from the eight algorithms above are very similar to each other. For simplification, Table 7 shows results of 6 algorithms only. Among the results, all the mean vegetation coverage values for each year in the study area $\left(V_{\mathrm{c}}\right)$ are exactly the same and equal those of the classification results, i.e. $65.62 \%$ in $1976,75.07 \%$ in 1989 and $73.18 \%$ in 2001.

To see the effect of atmospheric correction, let us have a close look at the so-called atmospherically corrected and converted mean vegetation index values $V_{\text {incut }}$ (underlined digits in Table 7). They are in the range of $0.0797-0.0951$, averaged 0.0860 for the year 1976; in the range of $0.1387-0.1589$, averaged 0.1487 for the year 1989; and in the range of $0.1512-0.1679$, averaged 0.1597 for the year 2001. However, for each algorithm, they are all small for 1976, great for 1989 and further great for 2001(only one exceptional value).

Comparing the mean vegetation index values of the corrected images $(0.0860,0.1487$ and 0.1597$)$ with those of the uncorrected images $(0.4122,0.4096$ and 0.1492$)$ for the different years, we know that the atmospheric effects were very great on the image of 1976 (absolute $\Delta V_{\mathrm{i}}=0.3262$ ), great on the image of 1989 (absolute $\Delta V_{\mathrm{i}}$ 
Table 7. Results of the corrected and converted mean vegetation index and coverage values for the study area in different years by six different algorithms.

\begin{tabular}{|c|c|c|c|c|c|c|}
\hline year & 1976 & 1989 & 2001 & 1976 & 1989 & 2001 \\
\hline & \multicolumn{3}{|c|}{ I. Each-year model \& two-step procedure } & \multicolumn{3}{|c|}{ III. 3-year-mean model \& two-step procedure } \\
\hline$V_{\mathrm{i} 0}$ & 0.4122 & 0.4096 & 0.1492 & 0.4122 & 0.4096 & 0.1492 \\
\hline$V_{\mathrm{i}}$ & 0.3603 & 0.3692 & 0.1547 & 0.2427 & 0.3066 & 0.3204 \\
\hline$V_{\text {in }}$ & 0.0853 & 0.1427 & 0.1590 & 0.0805 & 0.1435 & abnormal \\
\hline$V_{\text {incut }}$ & 0.0863 & 0.1451 & 0.1512 & 0.0806 & 0.1435 & 0.1679 \\
\hline \multirow[t]{2}{*}{$V_{\mathrm{c}}$} & 0.65615 & 0.75066 & 0.73181 & 0.65617 & 0.75069 & 0.73185 \\
\hline & \multicolumn{3}{|c|}{ IV. One-year model \& one-step procedure } & \multicolumn{3}{|c|}{ V. No-transition model \& one-step procedure } \\
\hline$V_{\mathrm{i} 0}$ & 0.4122 & 0.4096 & 0.1492 & 0.4122 & 0.4096 & 0.1492 \\
\hline$V_{\mathrm{i}}$ & 0.0951 & 0.1589 & 0.1570 & - & - & - \\
\hline$V_{\text {in }}$ & - & - & - & 0.0787 & 0.1367 & 0.1471 \\
\hline$V_{\text {incut }}$ & $0.0951^{*}$ & $0.1589^{*}$ & $0.1527^{*}$ & 0.0797 & 0.1387 & 0.1530 \\
\hline \multirow[t]{2}{*}{$V_{\mathrm{c}}$} & 0.65620 & 0.75070 & 0.73180 & 0.65620 & 0.75070 & 0.73180 \\
\hline & \multicolumn{3}{|c|}{ VI. 3-order model \& two- step procedure } & \multicolumn{3}{|c|}{ VII. 2-order model \& two-step procedure } \\
\hline$V_{\mathrm{i} 0}$ & 0.4122 & 0.4096 & 0.1492 & 0.4122 & 0.4096 & 0.1492 \\
\hline$V_{\mathrm{i}}$ & 0.3594 & 0.3757 & 0.1598 & 0.3610 & 0.3759 & 0.1601 \\
\hline$V_{\text {in }}$ & 0.0844 & 0.1491 & 0.1653 & 0.0861 & 0.1493 & 0.1658 \\
\hline$V_{\text {incut }}$ & 0.0861 & 0.1530 & 0.1667 & 0.0879 & 0.1532 & 0.1664 \\
\hline$V_{\mathrm{c}}$ & 0.65621 & 0.75070 & 0.73180 & 0.65625 & 0.75071 & 0.73180 \\
\hline
\end{tabular}

Note: $V_{\mathrm{i} 0}$ is the original, i.e. uncorrected vegetation index value. ${ }^{*}$ These values are, in fact, $V_{\text {icut }}$ values, because this one year model $\&$ one-step procedure did not output $V_{\text {in }}$ and $V_{\text {incut }}$, and its $V_{\text {icut }}$ values are comparable with general $V_{\text {incut }}$ values. This was due to closeness of the atmospheric conditions on the reception days of $09 / 21 / 2001$ in the study area and of 11/06/2001 in the reference area (Table 2).

$=0.2609$ ) but very small on the image of 2001 (absolute $\left.\Delta V_{\mathrm{i}}=0.0105\right)$. This result is also in accordance with the atmospheric conditions of the image reception days (Table 2). For example, the clear day of September 21, 2001 in the study area was the finest and also the closest to the clear day of November 6, 2001 in the reference area; and at the same time, the absolute $\Delta V_{\mathrm{i}}$ is also the smallest.

On the other hand, we also see that in comparison to the uncorrected ones, the corrected mean vegetation index values are always smaller in 1976 and 1989 but greater in 2001. Correspondingly, the $C$ correctors are negative in 1976 and 1989, but generally positive in 2001 . This indicates that the atmospheric conditions of the image-record days in the study area (Dandong) were worse on 09-15-1976 and on 09-12-1989, but better on 09-212001 than those of the day when the reference image was recorded in the reference area (11-06-2001 in Nanjing). This point can also be verified by the meteorological data in Table 2.

The image correction for different years in the study area serves to correct these images to the atmospheric conditions of the clear day of the reference image. Only after realizing this objective, can the results of vegetation index-coverage calculations be compared with each other and hereby be used for dynamic monitoring.

\subsection{Results of Plant Cover and Soil Erosion Monitoring and Discussions}

For monitoring of plant cover and soil erosion, the vegetation coverage grade maps, the soil slope grade map, and the soil erosion grade maps should be generated. The slope map was computed from a DEM, which was derived from digitization of topographic maps at the scale of 1:50,000 by an A0 digitizer. All the works was completed in the ENVI system and ArcGIS system.

To grade the vegetation coverage, ground slope, and soil erosion, we adopted the criterion formulated and modified by some researchers [23,30,37]. Its vegetation coverage grades are $<0.1,0.1-0.3,0.3-0.5,0.5-0.7$, $0.7-0.9$, and $>0.9$; its ground slope grades are $0^{\circ}, 1^{\circ}-3^{\circ}$, 
$3^{\circ}-5^{\circ}, 5^{\circ}-8^{\circ}, 8^{\circ}-15^{\circ}, 15^{\circ}-25^{\circ}, 25^{\circ}-35^{\circ}$, and $>35^{\circ}$; its soil erosion grades are: nearly none, slight, light, moderate, great, very great, serious. The relation of the soil erosion grades to the slope grades and the vegetation coverage grades is described in Table 8.

Using the criteria of vegetation coverage grading and the vegetation coverage maps (images) described in section 3.2, the vegetation coverage grade maps for different years can be generated. The working steps are as follows (please refer to Appendix also):

1) Wiping off data outside the study area and converting the vegetation coverage image into a format acceptable by Arcmap (in ENVI).

2) Generating the vegetation coverage grade map (image) (in Arcmap).

3) Computing the histogram of vegetation coverage grade map to obtain its statistics (in ENVI).

4) Assigning colors to the vegetation coverage grades (in ENVI).

5) Output color vegetation coverage grade map (in ENVI).

The results of various algorithms are all close to each other. For simplification, Table 9 lists the results of three algorithms only. From Tables $\mathbf{7}$ and $\mathbf{9}$, the process of vegetation change during 25 years from 1976 to 2001 can be seen clearly. The mean vegetation coverage values for each year, averaged by the pixels-statistical results of the 3 algorithms, was 0.65620 for 1976, 0.75069 in 1989 and 0.73181 in 2001 respectively (Table 7). So the process of change is that the mean vegetation coverage increased from 1976 to 1989 , i.e. from 0.6562 to 0.7507 , increasing by $14.40 \%$; but decreased a little from 1989 to 2001, i.e. from 0.7507 to 7318 , decreasing by $2.52 \%$.

Then we inspect the changes of different vegetation coverage grades. For simplification, we only take the results of the algorithm of the each-year model \& twostep procedure as an example. In Table 9 we can see that from 1976 to 1989 , the vegetation of coverage $<70 \%$ decreased from $51.21 \%$ to $26.54 \%$, decreasing by $48.17 \%$; whereas the vegetation of coverage $>70 \%$ in- creased from $48.79 \%$ to $73.46 \%$, increasing by $50.56 \%$. This implies that the area of medium-low coverage of vegetation decreased greatly and the area of high coverage of vegetation increased greatly, leading to improvement of the plant cover status. However, from 1989 to 2001, the vegetation of coverage $<70 \%$ increased from $26.54 \%$ to $35.69 \%$, increasing by $34.48 \%$; while the vegetation of coverage $>70 \%$ decreased from $73.46 \%$ to $64.31 \%$, decreasing by $12.46 \%$. But the vegetation of coverage $>90 \%$ still increased from $27.65 \%$ to $37.58 \%$, increasing by $35.91 \%$. This implies that the area of medium-low coverage of vegetation increased to a great extent and the area of high coverage of vegetation decreased to some extent, but the area of very high coverage of vegetation still increased to a great extent. That is to say, the vegetation status became a little bit worse or was basically stable or in a dynamic equilibrium from 1989 to 2001. With a closer look at the change of vegetation coverage $<70 \%$, we will see that the vegetation of coverage equaling $10 \%-30 \%, 30 \%-50 \%$, and $50 \%-$ $70 \%$ all decreased from 1976 to 1989 and increased from 1989 to 2001 . However, the vegetation of coverage < $10 \%$ increased continuously from 1976 through 2001 , i.e., $2.18 \%$ in $1976,3.84 \%$ in 1989 and $5.29 \%$ in 2001 .

The increase of vegetation coverage or the improvement of environment in the period of 1976-1989 was inconsistent with the general pattern in China. In the latter half of the 1970s, the ecological environment reached its worst condition, then gradually taking a turn for the better until now, as revealed by research works of us and others in Jiangxi Province and Anhui Province of China $[22,23,31,38]$. However, the decrease of vegetation coverage in the period of 1989-2001 was somewhat abnormal. The reason of the abnormality is that the study area is a city with its suburbs and besides, the suburbs are not large enough to attenuate the influences of urbanization. It is the urbanization that causes the abnormality. Since the 1980s, especially from the 1990s up to now, the city of Dandong and its suburbs have been seeing a more

Table 8. The relation of soil erosion grades to the slope grades and the vegetation coverage grades.

\begin{tabular}{ccccccccccc}
\hline & Slope grade $0^{\circ}$ & $1^{\circ}-3^{\circ}$ & $3^{\circ}-5^{\circ}$ & $5^{\circ}-8^{\circ}$ & $8^{\circ}-15^{\circ}$ & $15^{\circ}-25^{\circ}$ & $25^{\circ}-35^{\circ}$ & \\
\hline $\begin{array}{c}\text { Vegetation } \\
\text { coverage grade }\end{array}$ & & & & Soil erosion grade & & & & & \\
$<0.1$ & Nearly none & Slight & Moderate & Moderate & Great & Very great & Serious & Serious \\
$0.1-0.3$ & Nearly none & Slight & Light & Moderate & Moderate & Great & Very great & Serious \\
$0.3-0.5$ & Nearly none & Slight & Light & Light & Moderate & Moderate & Great & Very great \\
$0.5-0.7$ & Nearly none & Slight & Light & Light & Moderate & Moderate & Moderate & Great \\
$0.7-0.9$ & Nearly none & Slight & Light & Light & Light & Light & Light & Moderate \\
$>0.9$ & Nearly none & Slight & Slight & Slight & Slight & Slight & Slight & Light \\
\hline
\end{tabular}


Table 9. Statistics of vegetation coverage grades for different years in the study area, the Dandong city and its suburbs, obtained by three different algorithms.

\begin{tabular}{|c|c|c|c|c|c|c|c|}
\hline \multirow{2}{*}{ Grade } & \multirow{2}{*}{ Coverage range } & \multicolumn{3}{|c|}{ The number of pixels } & \multicolumn{3}{|c|}{ Area, $\%$} \\
\hline & & 1976 & 1989 & 2001 & 1976 & 1989 & 2001 \\
\hline & & \multicolumn{6}{|c|}{ I. each-year model \& two-step procedure } \\
\hline 1 & $<0.1$ & 22054 & 38799 & 53515 & 2.1814 & 3.8377 & 5.2933 \\
\hline 2 & $0.1-0.3$ & 64677 & 40463 & 49788 & 6.3974 & 4.0023 & 4.9247 \\
\hline 3 & $0.3-0.5$ & 109520 & 45733 & 79261 & 10.8330 & 4.5276 & 7.8400 \\
\hline 4 & $0.5-0.7$ & 321471 & 143268 & 178256 & 31.7978 & 14.1711 & 17.6319 \\
\hline 5 & $0.7-0.9$ & 404414 & 463180 & 270211 & 40.0019 & 45.8147 & 26.7275 \\
\hline 6 & $>0.9$ & 88850 & 279503 & 379955 & 8.7885 & 27.6466 & 37.5826 \\
\hline \multirow[t]{2}{*}{ Sum } & & 1010986 & 1010986 & 1010986 & 100.0000 & 100.0000 & 100.0000 \\
\hline & & \multicolumn{6}{|c|}{ II. each-year model \& one-step procedure } \\
\hline 1 & $<0.1$ & 26140 & 38850 & 55938 & 2.5856 & 3.8428 & 5.5330 \\
\hline 2 & $0.1-0.3$ & 68302 & 39559 & 46606 & 6.7560 & 3.9129 & 4.6100 \\
\hline 3 & $0.3-0.5$ & 102234 & 44552 & 75924 & 10.1123 & 4.4464 & 7.5099 \\
\hline 4 & $0.5-0.7$ & 317916 & 146972 & 180065 & 31.4461 & 14.5375 & 17.8108 \\
\hline 5 & $0.7-0.9$ & 422623 & 463328 & 282983 & 41.8031 & 45.8293 & 27.9908 \\
\hline 6 & $>0.9$ & 73771 & 277325 & 369470 & 7.2969 & 27.4311 & 36.5455 \\
\hline \multirow[t]{2}{*}{ Sum } & & 1010986 & 1010986 & 1010986 & 100.0000 & 100.0000 & 100.0000 \\
\hline & & \multicolumn{6}{|c|}{ IV. 3-order-model \& two-step procedure } \\
\hline 1 & $<0.1$ & 23119 & 42765 & 64326 & 2.2868 & 4.2300 & 6.3627 \\
\hline 2 & $0.1-0.3$ & 58237 & 34215 & 36355 & 5.7604 & 3.3843 & 3.5960 \\
\hline 3 & $0.3-0.5$ & 101099 & 39145 & 69162 & 10.0000 & 3.8720 & 6.8410 \\
\hline 4 & $0.5-0.7$ & 333456 & 139069 & 177934 & 32.9832 & 13.7553 & 17.6000 \\
\hline 5 & $0.7-0.9$ & 430111 & 507686 & 300820 & 42.5437 & 50.2169 & 29.7551 \\
\hline 6 & $>0.9$ & 64964 & 248111 & 362389 & 6.4258 & 24.5415 & 35.8451 \\
\hline Sum & & 1010986 & 1010986 & 1010986 & 100.0000 & 100.0000 & 100.0000 \\
\hline
\end{tabular}

extensive construction of buildings, roads, and highways, leading to destruction of vegetation and increase of bare land to an extent. However, in remote and mountainous regions, where the slope is steeper and the soil erosion is liable to take place, the vegetation coverage still increased after 1989, leading to very high percentage of the very dense vegetation (coverage $>90 \%$ ).

From the colorful maps of vegetation coverage grades for different years (Figure 8), we can see the vegetation changes clearly. For example, in 1976 the vegetation coverage was the lowest, because the red, pink, and yellow colors (vegetation of coverage equaling $0.1-0.7$ ) occupied more areas, while the green and dark green colors (the vegetation of coverage $>0.7$ ) being not so large. In 1989, the vegetation coverage became much better, as the decreases of the red, pink, and yellow colors and the increase of green and dark green colors revealed. However, in 2001, the area of red, pink and yellow colors increased again and the area of green colors decreased, too; but the area of dark green color (coverage $>0.9$ ) increased greatly. This indicates that the increase of lower coverage was almost compensated by the increase of very high coverage. As a result, the overall vegetation coverage during 1989 2001 remained almost unchanged or in a state of balance.

In the following part, we talk about the monitoring of 


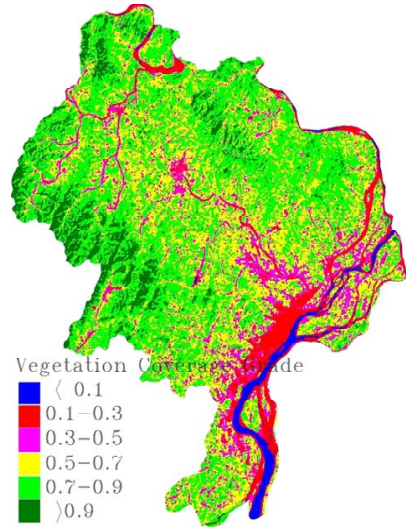

(a)

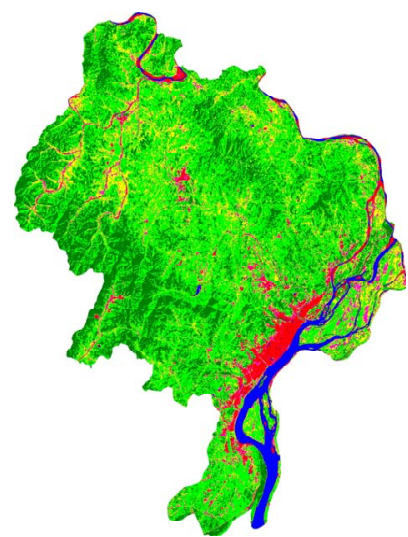

(b)

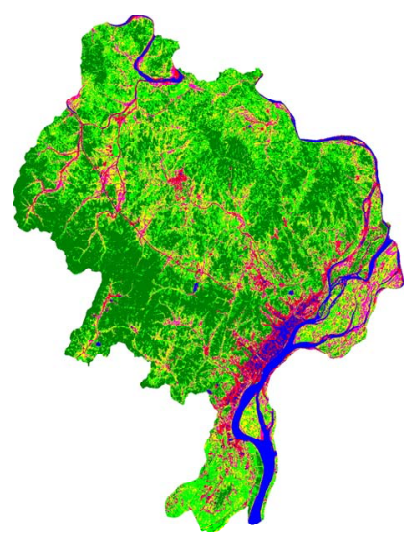

(c)

Figure 8. Maps of vegetation coverage grades for different years in the study area, the city of Dandong and its suburbs. Note: None of the maps attached to this paper can be formally taken as the basis of the national boundary between China and Korea. Please see details in the section 2.1) (a) 1976; (b) 1989; (c) 2001.

soil erosion. Based on the DEM derived from topographic maps and the existing vegetation coverage grade maps, we generated the slope map, slope grade map, and soil erosion grade maps. The working steps in detail are as follows (please refer to Appendix also):
1) Generating slope map from the DEM (in Arcmap);

2) Generating slope grade map from the slope map (in Arcmap);

3) Computing histogram of the slope grade map to obtain its statistics (in ENVI);

4) Changing the format of the vegetation coverage grade maps into a format acceptable by Arcmap (in ENIV);

5) Generating soil erosion grade maps from the slope grade map and the vegetation grade maps (in Arcmap);

6) Computing the histograms of the soil erosion grade maps to obtain their statistics (in ENVI);

7) Assigning colors to the soil erosion grade maps (in ENVI).

8) Output the colorful soil erosion grade maps (in ENVI).

Figure 9 shows the colorful slope grade map and colorful DEM concurrently. The statistics of the slope grade map indicate that the study area is composed of flat land, inclined hills, and steep mountains. The flat land of $0^{\circ}$ $\left(<0.5^{\circ}\right.$ in fact $)$ occupies around one-half of the area, i.e. $49.0641 \%$; the slightly inclined land $\left(1^{\circ}-3^{\circ}\right)$ occupies $9.0593 \%$; the lightly inclined land $\left(3^{\circ}-5^{\circ}\right)$ occupies $5.8539 \%$; the moderately inclined land $\left(5^{\circ}-8^{\circ}\right)$ occupies $7.3014 \%$; the very inclined slope land $\left(8^{\circ}-15^{\circ}\right)$ occupies $14.1595 \%$; the steep land $\left(15^{\circ}-25^{\circ}\right)$ occupies $11.3512 \%$; the very steep land $\left(25^{\circ}-35^{\circ}\right)$ occupies $2.8267 \%$; and the extremely steep land $\left(>35^{\circ}\right)$ only occupies $0.3839 \%$. These terrain characteristics can be seen clearly on the DEM, which was overlapped by a special color composite. The latter was derived from a special data transformation developed by Z. Y. Zeng [39,40]. On the composite, the three primary colors, i.e. the red, green and blue, denote the bare land, dense vegetation, and clear and deep water respectively. In turn, the three transitional colors, i.e. the yellow, pink and cyan, logically denote the sparse vegetation; wetland, turbid water, or buildings with shadows; and marsh, rice field, or other water surface plus aquatic plant. It should be emphasized that the relations of colors described here indicate those in optics or in colored light, not in dyestuff or pigment. In the latter, the three primary colors are red, yellow and blue; the three transitional colors are orange, purple, and green respectively [41]. Thus the DEM clearly shows the topography, terrain steepness, and ground cover of the study area as follows: in the north-east and south-west of the area, there are steeper mountains and hills covered by dense vegetation (green color). Between the mountains there is a river-let valley named Wulong, where gentle slopes or flat land are situated and ground is bare or with bright mature crops on it (red color). And at many places of the mountains, hills, and valley, there is also scattered sparse vegetation (yellow color) but its space extent is 


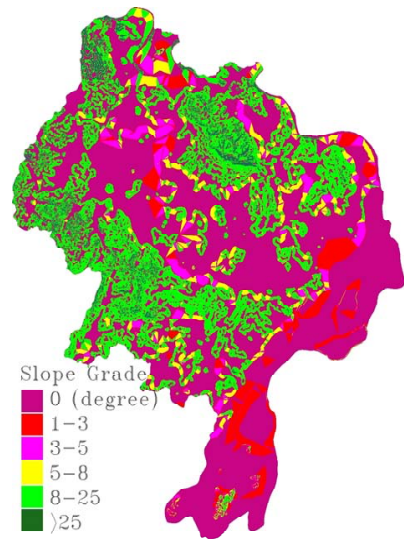

(a)

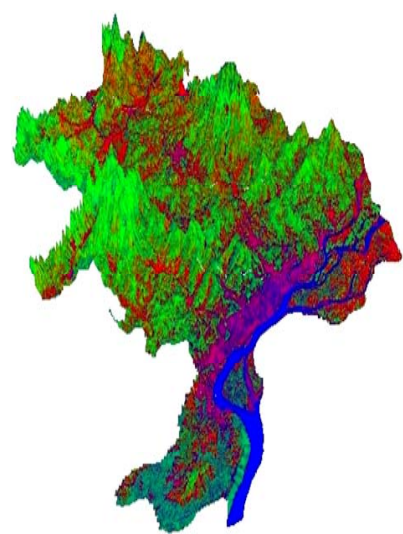

(b)

Figure 9. Cross-reference of the color slope grade map (a) and the color DEM (b) of the study area, city of Dandong and its suburbs. DEM was overlapped with a color composite: Red-bare land or light matured crops; Green-dense vegetation; Blue-water; Yellow-sparse vegetation; Cyan -rice field; Pink - wet and low bare land, or buildings with shadows. Urbanization (pink on DEM) occurred in the flat area and dense vegetation (green on DEM) covered steep terrain.

limited. Along the south-east edge of the area is the Yalujiang River (blue color) and its low and flat valley, where the city of Dandong and some towns are situated (pink color). Finally, at the southern end of the area, there is lower and flat land with vast paddy fields on it (cyan color).

Table 10 lists the soil erosion grades for different years, calculated by three algorithms only. We still take the result of the each-year model \& two-step procedure as an example for discussing soil erosion change. Figure 10 shows the color maps of soil erosion grades for different years. Please note that $49.0641 \%$ of the study area belongs to the grade of nearly-none erosion and it is always the same for all the monitoring years, because $49.0641 \%$ of the area lies in the flat land with slope of $0^{\circ}$. This kind of land has even turned into deposition areas in

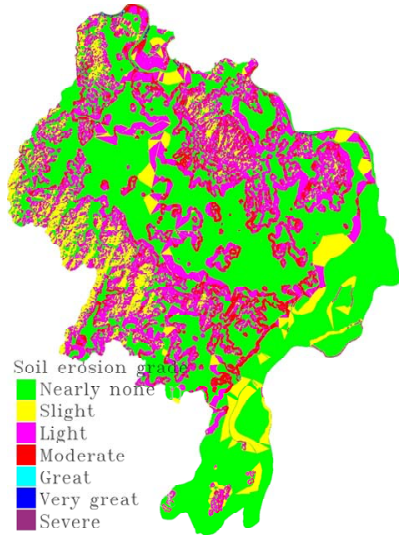

(a)

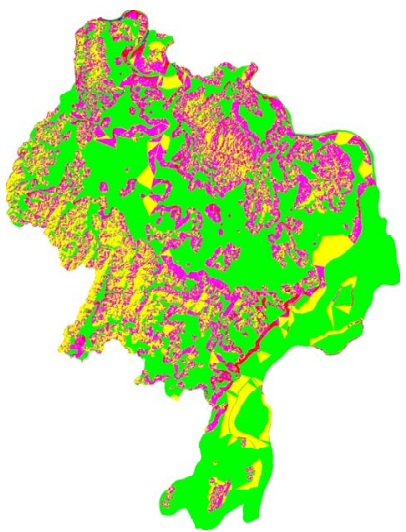

(b)

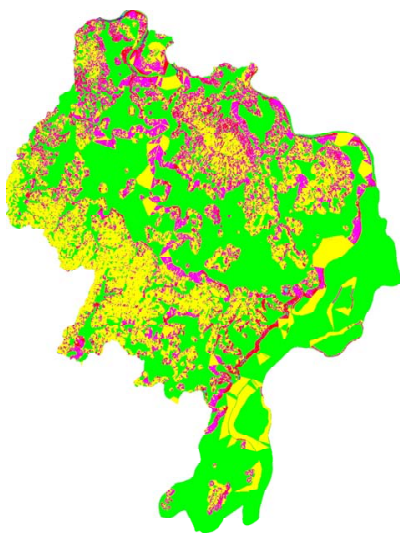

(c)

Figure 10. Maps of soil erosion grades for different years in the city of Dandong and its suburbs as a study area. (a) 1976; (b) 1989; (c) 2001.

many places, despite how the vegetation coverage is on it.

In the period from 1976 to 1989 and then to 2001, the overall area of erosion land, i.e. the sum of light, moderate, great, very great, and severe erosions decreased from $35.36 \%$ to $25.43 \%$ and then to $18.53 \%$. In other words, the erosion land was reduced by $47.60 \%$ in the period of 
Table 10. Statistics of soil erosion grades for different years in the study area, the city of Dandong and its suburbs, calculated by three different algorithms.

\begin{tabular}{|c|c|c|c|c|c|c|c|}
\hline \multirow{2}{*}{ Grade } & \multirow{2}{*}{ Erosion intensity - } & \multicolumn{3}{|c|}{ The number of pixels } & \multicolumn{3}{|c|}{$\%$} \\
\hline & & 1976 & 1989 & 2001 & 1976 & 1989 & 2001 \\
\hline & & \multicolumn{6}{|c|}{ I. Each-year model \& two-step procedure } \\
\hline 1 & Nearly none & 496031 & 496031 & 496031 & 49.0641 & 49.0641 & 49.0641 \\
\hline 2 & Slight & 157479 & 257912 & 327615 & 15.5768 & 25.5109 & 32.4055 \\
\hline 3 & Light & 271952 & 228782 & 147287 & 26.8997 & 22.6296 & 14.5686 \\
\hline 4 & Moderate & 82970 & 26264 & 36992 & 8.2068 & 2.5979 & 3.6590 \\
\hline 5 & Great & 1844 & 1241 & 2247 & 0.1824 & 0.1228 & 0.2223 \\
\hline 6 & Very great & 435 & 384 & 484 & 0.0430 & 0.0380 & 0.0479 \\
\hline 7 & Severe & 275 & 372 & 330 & 0.0272 & 0.0368 & 0.0326 \\
\hline \multirow[t]{2}{*}{ sum } & & 1010986 & 1010986 & 1010986 & 100.0000 & 100.0000 & 100.0000 \\
\hline & & \multicolumn{6}{|c|}{ II. Each-year model \& one-step procedure } \\
\hline 1 & Nearly none & 496031 & 496031 & 496031 & 49.0641 & 49.0641 & 49.0641 \\
\hline 2 & Slight & 146410 & 256693 & 322412 & 14.4819 & 25.3904 & 31.8908 \\
\hline 3 & Light & 280292 & 229778 & 152809 & 27.4246 & 22.7281 & 15.1148 \\
\hline 4 & Moderate & 82503 & 26500 & 36579 & 8.1606 & 2.6212 & 3.6182 \\
\hline 5 & Great & 2365 & 1228 & 2315 & 0.2339 & 0.1215 & 0.2290 \\
\hline 6 & Very great & 1990 & 386 & 506 & 0.1968 & 0.0382 & 0.0501 \\
\hline 7 & Severe & 1395 & 370 & 334 & 0.1380 & 0.0366 & 0.0330 \\
\hline \multirow[t]{2}{*}{ sum } & & 1010986 & 1010986 & 1010986 & 100.0000 & 100.0000 & 100.0000 \\
\hline & & \multicolumn{6}{|c|}{ V. No transition model \& one-step procedure } \\
\hline 1 & Nearly none & 496031 & 496031 & 496031 & 49.0641 & 49.0641 & 49.0641 \\
\hline 2 & Slight & 97010 & 194816 & 345712 & 9.5956 & 19.2699 & 34.1955 \\
\hline 3 & Light & 310771 & 291018 & 131482 & 30.7394 & 28.7856 & 13.0053 \\
\hline 4 & Moderate & 104251 & 26897 & 32433 & 10.3118 & 2.6605 & 3.2081 \\
\hline 5 & Great & 2096 & 1398 & 3981 & 0.2073 & 0.1383 & 0.3938 \\
\hline 6 & Very great & 460 & 840 & 893 & 0.0455 & 0.0435 & 0.0883 \\
\hline 7 & Severe & 367 & 386 & 454 & 0.0363 & 0.0382 & 0.0449 \\
\hline sum & & 1010986 & 1010986 & 1010986 & 100.0000 & 100.0000 & 100.0000 \\
\hline
\end{tabular}

25 years from 1976 to 2001 . The decrease of soil erosion area is contributed mainly by the decrease of the light erosion grade, which occupied $26.90 \%$ in $1976,22.63 \%$ in 1989 , and $14.57 \%$ in 2001 . It is yet worth paying attention to the fact that even from 1989 to 2001 , the soil erosion in the area was still lightened by $27.12 \%$, although in the same time the mean vegetation coverage was slightly reduced, i.e. from $75.07 \%$ to $73.18 \%$. This implies that the slight decrease of the vegetation cover- age did not lead to increase of soil erosion. The reason is that the vegetation coverage decrease chiefly resulted from urbanization and the latter mainly occurred on the flatland or gently sloping land, which could not cause a prominent increase of soil erosion due to the gentle steepness. However, in the more greatly sloping or steep regions, especially in the remote and mountainous areas, where the land is apt to be eroded due to greater steepness but rarely disturbed by urbanization, so the vegeta- 
tion coverage was still magnified. As a synthetic result, the area of soil erosion for the overall region tends to be reduced.

From Figure 10 we can see clearly that the soil erosion had been mitigated from 1976 to 1989 and then to 2001. This is revealed in the decrease of pink and red colors, i.e. light and moderate erosion areas and in the increase of the yellow colors, i.e. slight erosion area from 1976 to 1989 and then to 2001. Simultaneously, the areas of cyan, blue, and maroon colors, i.e. great, very great, and severe erosion grades have all changed but their space extent is too small to be visualized in Figure 10 unless the figure is enlarged. Note that from 1989 to 2001 , the increase of vegetation coverage $0.1-0.5$ (the red and pink colors in Figure 8) did not, by no means, lead to the increase of light and moderate erosion (pink and red colors in Figure 10). The reason for this has been explained.

Finally, we say several words about credibility of the method. The method was originally developed before the year 2001. It has been used and tested in the Lianshui basin of Jiangxi Province, China. Its monitoring results were compared with those of other researchers [31] and the comparison has proved that this method is correct, reliable, and more precise [22,23]. And now the method has been improving greatly in recent years. So the present method should be more perfect and precise than its original version and thus the present monitoring results should suit the actual conditions all the more. However, in the city of Dandong and its suburbs, there is no other researcher's result in the same space extent and same time interval to be compared with our results. Nevertheless, fortunately, few existing unpublished data with the whole Dandong Municipality $\left(14685.2 \mathrm{Km}^{2}\right)$, a part of which is our study area $\left(909.9 \mathrm{Km}^{2}\right)$, can be used to be compared with our results roughly. According to the unpublished reports of the Bureau of Soil and Water Conservation, Liaoning Province, September 29, 1997 and the Bureau of Water Resource, Dandong Municipality, January 11, 2000 and May 23, 2000, the soil erosion area, i.e. the sum of light, moderate, great, very great, and serious grade for the whole Dandong Municipality decreased from $33.4 \%$ in 1986 to $27.0 \%$ in 1996 , and then to $<27.0 \%$ in 2000 (visual air-photo interpretation result). According to our results, the soil erosion area for our study area decreased from $35.4 \%$ in 1976 to $25.4 \%$ in 1989 , and then to $18.5 \%$ in 2001 . When we put the two series of data together in an order, they were $35.4 \%$ in $1976,33.4 \%$ in $1986,25.4 \%$ in $1989,27.0 \%$ in 1996 , $<27.0$ in 2000 , and $18.5 \%$ in 2001 . It is obvious that the general trends and magnitudes of soil erosion change in the whole region (Dandong Municipality) and in the partial region (our study area) are consistent and almost fit to each other, even though the two series of data came from different space extent, different time interval, different researchers, and yet different methodology. We have also noticed that a few of the data drift a bit off the normal order of magnitude, i.e. the $27.0 \%$ in 1996 for Dandong Municipality was a bit greater than the $25.4 \%$ in 1989 for our study area. This may be caused by greater erosion in some areas outside the city of Dandong and its suburbs.

\section{Summary and Conclusions}

1) Traditional method of plant cover and soil erosion monitoring is mainly the visual photo or image interpretation or image classification. The accuracy of monitoring is lower and the amount of work is great. One may also adopt the USLE equation method. However, its ineffectiveness in applications outside the range of conditions for which it was developed and the hard evaluation of its factors $\mathrm{K}, \mathrm{C}, \mathrm{P}$ and $\mathrm{L}$ restrict its application. It is for these reasons that we suggested a new method as one of choices. This method suggests finding one or more variables free from atmospheric effects as a starting point to reduce atmospheric correction parameters. This is an indirect, fast and operational way, through a series of modeling, simulation and correction, to obtain the due atmospheric correction parameters and then correct images, calculate vegetation index and vegetation coverage values for all pixels, so that the monitoring of vegetation and soil erosion can be realized effectively.

2) We have already found some variables free from atmospheric effects, e.g. the mean vegetation coverage value of the whole study area. The latter is only the spatial distribution of vegetation and can be obtained directly from the satellite image itself. For one-date image of a study area, only one value of the mean vegetation coverage is needed. So it is easier to acquire, e.g. in this study it was acquired by unsupervised classification and broken line analysis.

3) Using the mean vegetation coverage values for the study area as a starting point, one can conduct a series of simulative calculations, so that the corresponding correct mean vegetation index values and the due atmospheric correction parameters for the area can be deduced. However, to conduct the simulative calculations, one needs a series of models in advance. All the needed models, e.g. the models of relation between vegetation coverage and vegetation index, the models of relation of vegetation index values between the reference area and the study area (or any other new area), the difference coefficients of atmospheric effects on different bands, etc., have been established in this research.

4) Supposing some mean atmospheric corrector $C$ val- 
ues, the simulative calculations can be carried out. Based on the series of resulting simulated data pairs, a series of new model can be structured. Among them, the important ones are $V_{\mathrm{i}}=f\left(V_{\mathrm{c}}\right), C=f\left(\Delta V_{\mathrm{i}}\right)$, and $C=f\left(V_{\mathrm{c}}\right)$. By using these new models and the so-called correct mean vegetation coverage values $V_{\mathrm{c}}$ obtained from classification, one can compute out the due mean vegetation index values and the due atmospheric correction parameters for the study area and for different years.

5) By substituting the numerator and denominator correctors $a$ and $b$ values for the calculation formula of NDVI, one can obtain the atmospherically corrected vegetation index and coverage values for all pixels and their maps for different years. Then the vegetation coverage grade maps for different years can be obtained and the vegetation monitoring was realized. Furthermore, using the resulting vegetation grade maps and a slope grade map from DEM, one can obtain the soil erosion grade maps for different years and so the soil erosion monitoring was also realized.

6) Our monitoring results, including the statistics of vegetation index, vegetation coverage, and soil erosion as well as the color maps of vegetation coverage and soil erosion, are all reasonable and interesting, clearly and in detail showing the change of vegetation and soil erosion in the study area in the 25 years from 1976 to 2001. The results also coincide with the existing other investigation results and correspond to reality.

7) The essence of atmospheric correction in this method is that using vegetation index values in a clear day and corresponding vegetation coverage values to establish a vegetation index-coverage relation, the relation can be regarded as a standard one in a clear day; and then correcting vegetation index values of other area to be appropriate for the standard relation, the corrected vegetation index values can be regarded as ones of a clear day.

8) For this method to be perfected and extensively applied, some research works are still needed. However, as we have emphasized, the essence of this method is to acquire the so-called correct mean vegetation coverage value free from atmospheric effects for the study area and then based on this value to rationally "assign" or "distribute" appropriate vegetation coverage values to all pixels. So the atmospheric correction and the vegetation index calculation are merely a means or bridge for fulfilling this task. Therefore, other things are not so important, provided the more rational "distribution" work is done. Even so, the atmospheric correction and vegetation index calculation by this method are still credible.

\section{Acknowledgements}

We are grateful to the National Fund for Natural Sci- ences of China, which sponsored our research (Project numbers: 40071043, 40371053 \& 41071281). We are also grateful to Global Land Cover Facility, Institute for Advanced Computer Studies, University of Maryland, USA for offering some images via internet. We also acknowledge the Bureau of Soil and Water Conservation, Liaoning Province and the Bureau of Water Resource, Dandong municipality for a few data cited. We are also thankful to the anonymous reviewers for valuable suggestions and comments.

\section{REFERENCES}

[1] J. R. Fan, J. H. Zhang, X. H. Zhong, S. Z. Liu and H. P. Tao, "Monitoring of Soil Erosion and Assessment for Contribution of Sediments to Rivers in a Typical Watershed of the Upper Yangtze River Basin," Land Degrad \& Develop, Vol. 15, No. 4, 2004, pp. 411-421.

[2] O. Cerdan, N. Baghdadi, C. King and A. Couturier, "Soil Erosion Modeling at the Catchment Scale Using Remote Sensing," Geophysical Research Abstracts, Vol. 7, 2005.

[3] Z. Y. Jiang, A. R. Huete, J. Chen, Y. H. Chen, J. Li, G. J. Yan and X. Y. Zhang, "Analysis of NDVI and Scaled Difference Vegetation Index Retrievals of Vegetation Fraction," Remote Sensing of Environment, Vol. 101, No. 3, 2006, pp. 366-378. doi:10.1016/j.rse.2006.01.003

[4] A. Goener, R. Gloaguen and F. Makeschin, "Monitoring of the Ecuadorian Mountain Rainforest with Remote Sensing," Journal of Applied Remote Sensing, Vol. 1, No. 1, 2007.

[5] N. B. Chang, M. Han, W. Yao, L. C. Chen and S. G. Xu, "Change Detection of Land Use and Land Cover in an Urban Region with SPOT-5 Images and Partial Lanczos Extreme Learning Machine," Journal of Applied Remote Sensing, Vol. 4, No. 1, 2010.

[6] C. G. Homer, C. L. Aldridge, D. K. Meyer and S. J. Schell, "Multi-Scale Remote Sensing Sagebrush Characterization with Regression Trees over Wyoming, USA: Laying a Foundation for Monitoring," International Journal of Applied Earth Observation and Geoinformation, Vol. 14, No. 1, 2012, pp. 233-244. doi:10.1016/j.jag.2011.09.012

[7] M. A. J. Wulder, C. White, S. Coggins, S. M. Ortlepp and N. C. Coops, "Digital High Spatial Resolution Aerial Imagery to Support Forest Health Monitoring: The Mountain Pine Beetle Context," Journal of Applied Remote Sensing, Vol. 6, No. 1, 2012, Article ID: 062527.

[8] R. B. King, "Land Cover Mapping Principles: A Return to Interpretation Fundamentals," International Journal of Remote Sensing, Vol. 23, No. 18, 2002, pp. 3525-3545. doi:10.1080/01431160110109606

[9] G. Rees, M. Williams and P. Vitebsky, "Mapping Land Cover Change in a Reindeer Herding Area of the Russian Arctic Using Landsat TM and ETM+ Imagery and Indigenous Knowledge," Remote Sensing of Environment, Vol. 85, No. 4, 2003, pp. 441-452.

doi:10.1016/S0034-4257(03)00037-3 
[10] J. D. Tarpley, S. R. Schneider and R. L. Money, "Global Vegetation Indices from NOAA-7 Meteorological Satellite," Journal of Climate and Applied Meteorology, Vol. 23, No. 3, 1984, pp. 491-494. doi:10.1175/1520-0450(1984)023<0491:GVIFTN $>2.0 . C$ $\underline{\mathrm{O} ; 2}$

[11] J. R. G. Townshend, T. E. Goff and C. J. Tucker, "Multitemporal Dimensionality of Images of Normalized Difference Vegetation Index at Continental Scales," IEEE Transactions on Geoscience and Remote Sensing, Vol. 23, No. 6, 1985, pp. 888-895. doi:10.1109/TGRS.1985.289474

[12] N. A. Drake, X. Y. Zhang, E. Berkhout, R. Bonifacio, D. I. F. Grimes, J. Wainwright and M. Mulligan, "Modelling Soil Erosion at Global and Regional Scales Using Remote Sensing and GIS Techniques," In: P. M. Atkinson and N. J. Tale, Eds., Advances in Remote Sensing and GIS Analysis, John \& Sons, New York, 1999, pp. 241-261.

[13] B. C. Rundquist, "The Influence of Canopy Green Vegetation Fraction on Spectral Measurements over Native Tall Grass Prairie," Remote Sensing of Environment, Vol. 81, No. 1, 2002, pp. 129-135. doi:10.1016/S0034-4257(01)00339-X

[14] P. P. Singh, S. Roy and F. N. Kogan, "Vegetation and Temperature Condition Indices from NOAA AVHRR Data for Drought Monitoring over India," International Journal of Remote Sensing, Vol. 24, No. 22, 2003, pp. 4393-4402. doi:10.1080/0143116031000084323

[15] P. Durante, C. Oyonarte and F. Valladares, "Influence of Land-Use Types and Climatic Variables on Seasonal Patterns of NDVI in Mediterranean Iberian Ecosystems," Journal of Applied Vegetation Science, Vol. 12, No. 2, 2009, pp. 177-185.

[16] G. X. Wang, G. Gertner, S. F. Fang and A. B. Anderson, "Mapping Multiple Variables for Predicting Soil Loss by Geostatistical Methods with TM Images and a Slope Map," Photogrammetric Engineering \& Remote Sensing, Vol. 69, No. 8, 2003, pp. 889-898.

[17] R. L. Gaffer, D. C. Flanagan, M. L. Denight and B. A. Engl, "Geographical Information System Erosion Assessment at a Military Training Site," Journal of Soil and Water Conservation, Vol. 63, No. 1, 2008, pp. 1-10. doi:10.2489/jswc.63.1.1

[18] M. F. Winchell, S. H. Jackson, A. M. Wadley and R. Srinivasan, "Extension and Validation of a Geographic Information System-Based Method for Calculating the Revised Universal Soil. Loss Equation Length-Slope Factor for Erosion Risk Assessments in Large Watershed," Journal of Soil and Water Conservation, Vol. 63, No. 3, 2008, pp. 105-111. doi:10.2489/jswc.63.3.105

[19] S. K. Saha, "Water and Wind Induced Soil Erosion Assessment and Monitoring Using Remote Sensing and GIS," In: M. V. K. Sivakumar, P. S. Roy, K. Harsen and S. K. Saha, Eds., Satellite Remote Sensing and GIS Application in Agricultural Meteorology, Dehra Dun, 2004, pp. 315330 .

[20] M. K. Hazarika and K. Honda, "Estimation of Soil Erosion Using Remote Sensing and GIS, Its Valuation and
Economic Implications on Agricultural Production," In: D. E. Stott, R. H. Mohtar and G. C. Steinhardt, Eds., Sustaining the Global Farm, 2001, pp. 1090-1093.

[21] R. Quiñonez-Piñón, A. Mendoza-Durán and C. Valeo, "Design of an Environmental Monitoring Program Using NDVI and Cumulative Effects Assessment," International Journal of Remote Sensing, Vol. 28, No. 7, 2007, pp. 1643-1644. doi:10.1080/01431160600887730

[22] Z. Y. Zeng, "Fully Automatic Mapping for Vegetation and Soil Erosion Monitoring Using Remote Sensing, Mathematical Modelling and GIS Techniques," Proceedings of the 20th international cartographic conference: Mapping the 21st Century, Beijing, 6-10 August 2001, pp. 702-709.

[23] Z. Y. Zeng, "2004. Study on Computer Classification of Satellite Images and Application in Geoscience," Science Press, Beijing, 2004. (In Chinese).

[24] R. E. Turner and M. M. Spencer, "Atmospheric Model for Correction of Spacecraft Data," Proceedings of the Eighth International Symposium on Remote Sensing of Environment, Ann Arbor, 2-6 October 1972.

[25] K. J. Thome, D. L. Helder, D. Aaron and J. D. Dewald, "Landsat-5 TM and Landsat-7 ETM+ Absolute Radiometric Calibration Using the Reflectance-Based Method," IEEE Transactions on Geoscience and Remote Sensing, Vol. 42, No. 12, 2004, pp. 2777-2785. doi:10.1109/TGRS.2004.839085

[26] E. Vermote, D. Tanre, J. L. Deuze, M. Herman and J. J. Morcette, "Second Simulation of the Satellite Signal in the Solar Spectrum: An Overview," IEEE Transactions on Geoscience and Remote Sensing, Vol. 35, No. 3, 1997, pp. 675-686. doi:10.1109/36.581987

[27] U. S. Geological Survey, "Landsat Data Users Handbook," EROS Data Center, Sioux Falls, 1979, pp. 33-38.

[28] Y. Kaufman, "The Atmospheric Effect on Remote Sensing and Its Correction," In: G. Asrar, Ed., Theory and Applications of Optical Remote Sensing, John Wiley, New York, 1989, pp. 336-428.

[29] P. M. Mather, "Remote Sensing and Geographical Information Systems," In: P. M. Mather, Ed., TERRA-I: Understanding the Terrestrial Environment, Taylor \& Francis, London-Washington DC, 1992, pp. 211-219.

[30] Z. G. Wang, Z. H. Hu, Z. Y. Wei, J. R. Xu, C. H. Wang and Z. G. Ren, "Soil Erosion Control and Damland System Agriculture in Weijiayu Watershed," In: J. M. Laflen, J. L. Tian and C. H. Huang, Eds., Soil Erosion and Dryland Farming, CRC Press, Boca Raton, London, New York, Washington DC, 2000, pp. 81-91.

[31] D. C. Li and D. M. Shi, "Application of Satellite Remote Sensing Techniques for Monitoring Dynamic Change of Soil Erosion in Xingguo County," Soil and Water Conserv in China, Vol. 2, No. 1, 1998, pp. 29-32 (in Chinese).

[32] P. Heckbert, "Color Image Quantization for Frame Buffer Display," Computer Graphics, Vol. 16, No. 3, 1982, pp. 297-307. doi:10.1145/965145.801294

[33] ILWIS Department, International Institute for Aerospace 
Survey and Earth Sciences (ITC), "ILWIS 2.1 for Windows, The Integrated Land and Water Information System," User's Guide, Enschede, 1997, pp. 213-216.

[34] D. S. Liu and Z. Y. Zeng, "Mathematic Method and Modelling in the Research of Soil and Environment," Agriculture Press, Beijing, 1987, pp. 197-202 (in Chinese).

[35] Z. J. Gu, Z. Y. Zeng, X. Z. Shi, D. S. Yu, W. Zheng, Z. L. Zhang and Z. F. Hu, "A Model Calculating Vegetation Fractional Coverage from ETM+ Imagery," Frontiers in Ecology and the Environment, Vol. 17, No. 2, 2008, pp. 771-776. (In Chinese)

[36] Z. J. Gu, Z. Y. Zeng, X. Z. Shi, D. S. Yu, W. Zheng, Z. L. Zhang and Z. F. Hu, "Estimation Models of Vegetation Fractional Coverage (VFC) Based on Remote Sensing Image at Different Radiometric Correction Level," Chinese Journal of Applied Ecology, Vol. 19, No. 6, 2008, pp. 1296-1302 (in Chinese).

[37] Z. X. Zhang, X. L. Peng, X. F. Chen and J. Y. liu, "Mountain Soil Erosion Mapping in Central Tibet Using Remote Sensing and GIS," The 4th International Symposium on High Mountain Remote Sensing Cartography, Karlstad-Kirula-Troms, 19-29 August 1996, pp. 255-263. http://www.kfunigrazac.at/geowww/hmrst/pdfs/hmvsc4/z hEA.hm4.PDF

[38] D. C. Li, X. R. Shi and B. Zhou, "Dynamic Monitoring of Soil Erosion in Mountains and Hills Area in the Southern China Using Remote Sensing," Proceedings of the 8th National Symposium on Remote Sensing, Nanning, 19-25 December 1993, pp. 324-327 (in Chinese).

[39] Z. Y. Zeng, "A New Method of Data Transformation for Satellite Images: I. Methodology and Transformation Equations for TM Images," International Journal of Remote Sensing, Vol. 28, No. 18, 2007, pp. 4095-4124. doi:10.1080/01431160601028912

[40] Z. Y. Zeng, "A New Method of Data Transformation for Satellite Images: II. Transformation Equations for SPOT, NOAA, IKONOS, Quick Bird, ASTER, MSS and Other Images and Application," International Journal of Remote Sensing, Vol. 28, No. 18, 2007, pp. 4125-4155. doi: 10.1080/01431160601030082

[41] L. Zhang and Z. C. Li, "The English-Chinese Technical and Scientific Dictionary," Chemical Industry Press, Beijing, 1997 (in Chinese). 


\section{Appendix}

Our practical working procedures of using ENVI and ArcGIS (Arcmap) systems for realizing the monitoring of plant cover and soil erosion (At present, no software package is offered for the algorithms)

\section{Appendix A}

Image correction and map calculation of vegetation index and vegetation coverage in ENVI processing system

1) Image correction and map calculation of vegetation index: taking $\mathrm{C}=1(\mathrm{a}=0.3566$ and $\mathrm{b}=-2.0)$ and ETM+ image of Sept. 12, 2001 as an example

ENVI--basic tools--band math--enter an expression-(float (b2)-b1- $\underline{0.3566}$ )/(float (b2) + b1 + 2.0)--input b1: TM3--input b2:TM4--output file: vid01--ok

2) Calculation of histogram statistics

ENVI--basic tools - statistics--compute statistics--input file:vid01--select mask band: ddbound (boundary fife for the application area)--ok--calculate histogram--histogram plot--text report--file--ok

3) Conversion of the vegetation index map from the application area to that of the reference area

ENVI--basic tools--band math--enter an expression-$\underline{0.939256816379 * \mathrm{~b} 0 * \mathrm{~b} 0 * \mathrm{~b} 0+0.5444966933 * \mathrm{~b} 0 *}$ $\underline{\mathrm{b} 0}+0.678468076 * \mathrm{~b} 0+0.003068975$--ok--inputb0: vid01--output file: vid01n--ok--basic tools--... (compute histogram, ditto)

4) Using relevant thresholds to cut the too small or too great values in the map

ENVI--basic tools--band math--enter an expression-(b0 LT $(-0.22528)) *(-0.22528)+($ b0 GT 0.36572) * $0.36572+((\mathrm{b} 0 \mathrm{GE}(-0.22528)$ AND (b0 LE 0.36572)) * b0--ok--inputb0: vid01n--output file: vid01ncut--basic tools--... (compute histogram, ditto)

5) Calculation of vegetation coverage map from the corrected and converted vegetation index map

ENVI--basic tools--band math--enter an expression-$\underline{6.487093360864 * \mathrm{~b} 0 * \mathrm{~b} 0 * \mathrm{~b} 0 * \mathrm{~b} 0-6.172463983663 *}$

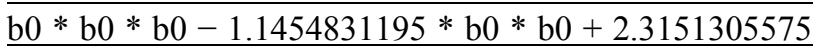
* b0 + 0.492401042--ok--inputb0:vd01ncut-outputfile: vcd01-basic tools--... (compute histogram, ditto)

\section{Appendix B}

Generation of vegetation coverage grades map (image) and slope grades map in ENVI system and ArcGIS system: taking the vegetation coverage grades map as an example

1) Wiping off data outside the area and changing the vegetation coverage image into a format acceptable by Arcmap in ENVI

ENVI--basic tools--band math--enter an expression-b0 * b9--ok--input b0:vcd01--input b9: ddbound--output file: vcd01a (a means area)--ok-file (in image frame) --save file as--TIFF-

2) Generation of vegetation coverage grades image in ArcGIS

Arcmap--ok (empty map)-- + (input map):vcd01at-add-yes (create pyramid)--spatial analyst-reclassify--

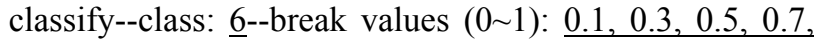
0.9, 1.0--ok--save as type--TIFF--output raster--name: vcd01atg (g means grade)--save--ok--x(exit)--no

3) Wiping off data outside the area and changing the vegetation coverage grades image into a format acceptable by Arcmap in ENVI

ENVI--basic tools--band math--enter an expression-b0 * b9 —ok--input b0: Vcd01atg--input b9: ddbound-output file: vcd01atga (a means area)--ok--file (in image frame)--save file as--TIFF-name: vcd01atgat--ok--basic tools-(compute histogram, ditto)

\section{Appendix C}

Generation of soil erosion grades map (image) in ArcGIS system and its color map in ENVI system

1) Generating all the possible combinations of vegetation coverage grades and slope grades for each erosion grade

Arcmap--ok(empty map)-- + (input map): vcd01atgat $(1,2,3,4,5,6)--Y e s--+$ (input map): ddslopeg (slope grades map of the area: $1,2,3,4,5,6,7,8)$--confirm-spatial analyst--raster calculator--vcd01atgat (double hit) --*--10-- + --ddslopeg-evaluate - calculation (hit right key)--data--export data--format: TIFF--name: erod01-save--yes (add map as a layer) (Result: the combination of $11,21,31,41,51$ and 61 belong to the grade of "Nearly none"; the combination of $12,22,32,42,52$, $62, \cdots, 66$ and 67 belong to the grade of "slight"; etc.)

2) Adding all combinations of each erosion grade together

All layers except erod01(hit right key for each)--remove--spatial analyst--raster calculator--erod01 (double

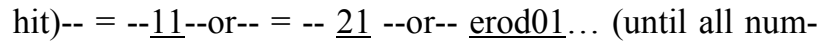
bers of the class "nearly none" are calculated)--evaluate --calculation(double hit)--backspace or delete--rename:

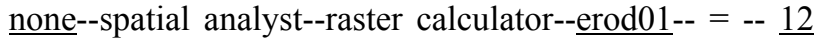
--or--erod0... (until all numbers of the class "slight" are calculated) - evaluate--calculation (double hit)--backspace or delete--rename: slight--spatial analyst--raster calculator--erod01-- = --23--or--erod01... (until all numbers of the class "light" are calculated)--evaluate--calculation (hit two times)--backspace or delete--rename:

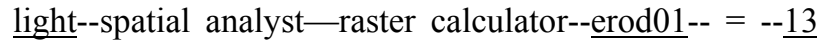
--or--erod01... (until all numbers of the class "moderate" are calculated)--evaluate--calculation(double hit)--backspace or delete--rename: moderate--spatial analyst--raster calculator--erod01-- = --15--or--erod01... (until all num- 
bers of the class "great" are calculated) - evaluate--calculation (double hit)--backspace or delete--rename: great --spatial analyst--raster calculator-- $=-$-16--or--erod01... (until all numbers of the class "very great" are calculated)--evaluate - calculation (double hit)--backspace or delete--rename: very great--spatial analyst--raster calculator--erod01-- $=--17--$ or - erod01... (until all numbers of the class "extremely great" are calculated)--evaluate-calculation(double hit)--backspace or delete--rename: extremely great

3) Merging all the grades into a soil erosion grades map

Spatial analyst--raster calculator-"none"-- + "slight"--*--2-- + "light"--*--3 + "moderate"---* --4-- + "great"--*-- $\underline{-}--+$ "very great"--*--6-- + "extremely great" --*--7--evaluate-calculation (hit right key)--data--export

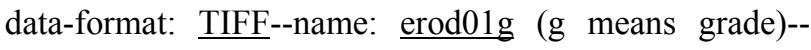
save--yes--no

\section{Appendix D}

Generation and output of color vegetation coverage grades map or soil erosion grades map in ENVI system

1) Assign colors to vegetation coverage grades map

ENVI--file--new file--vcd01atgat--tools (in the image frame)--color mapping--density slice--vcd01atgat 0 to 0,1 to 1,2 to 2,3 to 3,4 to 4,5 to 5,6 to 6 --edit range - white (red, green, blue)--ok--apply (ditto), blue, red, magenta, yellow, green, dark green...

2) Assign colors to soil erosion grades map

ENVI--file--new file--erod01g--tools (in the image frame)--color mapping--density slice-erod01g--0 to 0,1 to 1,2 to 2,3 to 3,4 to 4,5 to 5,6 to 6,7 to 7 --edit range--white, green, yellow, magenta, red, cyan, maroon --ok--apply (ditto), ...

3) Output their color maps and calculate their histograms (omitted) 